\title{
Controlled synthesis of a core-shell nanohybrid for effective multimodal image-guided combined photothermal/photodynamic therapy of tumors
}

\author{
Qian Cheng ${ }^{1}$, Zi-Hao Li', Yun-Xia Sun ${ }^{1}$ and Xian-Zheng Zhang (i) ${ }^{1}$
}

\begin{abstract}
In this paper, a simple strategy is proposed to prepare a core-shell nanohybrid (PB@PCN) by the controllable coating of zirconium-porphyrin (PCN) shells on Prussian blue (PB) nanoparticles. By adjusting the thickness of the PCN shell, the PB@PCN nanohybrid with the best comprehensive performance was obtained for tumor treatment and imaging. The integrated nanosystem as a tandem catalyst is able to convert $\mathrm{H}_{2} \mathrm{O}_{2}$ to $\mathrm{O}_{2}$ through the PB core, and then the $\mathrm{O}_{2}$ is directly injected into the PCN framework, leading to a high quantum yield of singlet oxygen to kill tumor cells and attack heat shock proteins (HSPs). The nanohybrid was further camouflaged by a tumor cell membrane (PB@PCN@MEM) with good immune evasion and active targeting ability. Upon accumulation at the tumor site, PN@PCN@MEM showed an enhanced photodynamic therapeutic effect against hypoxic tumor cells. Furthermore, coupled with the photothermal therapy of PB, photothermal/photodynamic synergistic therapy of tumors can be realized. In addition, due to its excellent imaging performance, this core-shell nanohybrid can be employed for the multimodal image-guided therapy of tumors.
\end{abstract}

\section{Introduction}

Tumors, as one of the deadliest diseases worldwide, seriously threaten the health of human beings. Engineering nanoparticles (NPs) that can selectively detect and efficiently destroy tumor cells in the body has been gaining momentum in the area of tumor therapy ${ }^{1-3}$. Driven by this, an increasing number of researchers have devoted themselves to developing multifunctional nanomaterials for tumor diagnosis and treatment ${ }^{4-6}$. Among them, core-shell nanohybrids have received tremendous attention due to the integration of multiple functionalities into the nanohybrid that go beyond the intrinsic limitations of individual components in the imaging and treatment of tumors ${ }^{7-10}$. Considering that the shell thickness will greatly affect the performance of the core-shell nanohybrid, it is of critical importance to

Correspondence: Xian-Zheng Zhang (xz-zhang@whu.edu.cn)

${ }^{1}$ Key Laboratory of Biomedical Polymers of Ministry of Education \& Department of Chemistry, Wuhan University, 430072 Wuhan, P. R. China

These authors contributed equally: Qian Cheng, Zi-Hao Li control the shell structure while integrating functionality into nanohybrids ${ }^{11-15}$.

Light-driven therapeutics have attracted increasing attention due to their obvious advantages for tumor treatment, including negligible invasiveness, precise spatial-temporal selectivity, and a reduced number of side effects ${ }^{16-20}$. Photodynamic therapy (PDT) and photothermal therapy (PTT), as the most representative methods of phototherapy, have become powerful tools for tumor treatment, and growing efforts have been devoted to combining PTT and PDT to yield effective therapeutic synergism $^{21}$. With the rapid development of nanotechnology, there is great interest in developing multifunctional core-shell nanohybrids with both photothermal and photodynamic properties ${ }^{22-24}$. However, in addition to the complex synthesis process, there are still several inherent limitations that need to be overcome. First, the hypoxic nature of the tumor microenvironment (TME) that is caused by the rapid proliferation of tumor cells and distorted tumor vessels, is 
highly detrimental to oxygen $\left(\mathrm{O}_{2}\right)$-dependent $\mathrm{PDT}^{25-29}$. Second, heat shock proteins (HSPs), which are upregulated after PTT, can enable tumor cells to resist heatinduced apoptosis, leading to actual performance compromise $^{30-32}$. Therefore, how to effectively integrate multiple components on the nanometer scale to obtain core-shell nanohybrids with the capability of overcoming these impediments is of great significance in combined $\mathrm{PDT} / \mathrm{PTT}$ tumor therapy.

To overcome the multiple limitations of combined PTT/PDT therapy and maximize the synergy between the core and the shell of the nanohybrid, a strategy for the controllable coating of a zirconium-porphyrin (PCN) shell on Prussian blue (PB) NPs has been proposed. Through a straightforward strategy, a series of PB@PCN nanohybrids with different shell thicknesses were prepared. The PB@PCN nanohybrid with the optimal shell thickness was further camouflaged by mouse colon cancer cell (CT26) membranes (PB@PCN@MEM) to endow the nanohybrid with good immune evasion and an active targeting ability $^{33-35}$. As illustrated in Scheme 1, the PCN shell, with the advantages of facile diffusion of singlet oxygen $\left({ }^{1} \mathrm{O}_{2}\right)$, avoidable self-quenching and high photosensitizer (PS) loading, could efficiently convert $\mathrm{O}_{2}$ into highly toxic ${ }^{1} \mathrm{O}_{2}$ to kill tumor cells by PDT and attack HSPs to promote the PTT effect ${ }^{36}$. In addition, the PB core could not only be used for PTT in tumors under near-infrared (NIR) irradiation but also convert the endogenous hydrogen peroxide $\left(\mathrm{H}_{2} \mathrm{O}_{2}\right)$, which is overproduced in tumor cells, into $\mathrm{O}_{2}{ }^{37}$. The generated $\mathrm{O}_{2}$ effectively relieves tumor hypoxia to enhance the therapeutic efficiency of PDT. In addition, PB@PCN@MEM could be used with multiple imaging techniques, including magnetic resonance

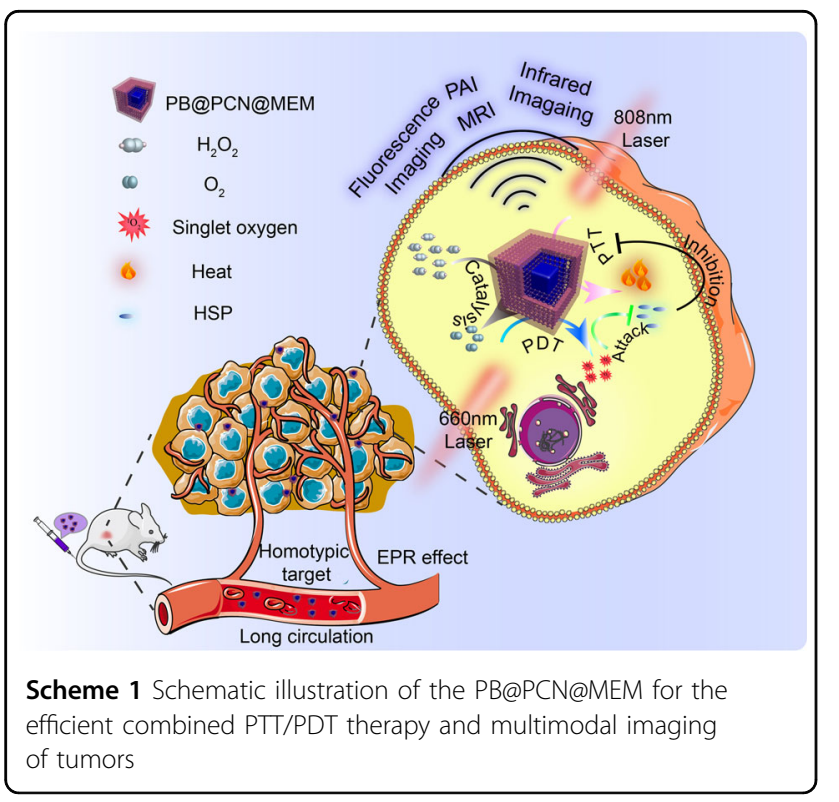

imaging (MRI), fluorescence imaging (FL), photoacoustic imaging (PAI), and infrared imaging (IR), providing detailed information about the tumor and leading to improved PTT/PDT therapy.

\section{Materials and methods \\ Materials and instrumentations}

Dimethyl formamide (DMF), dimethyl sulfoxide (DMSO), $\mathrm{K}_{3}\left[\mathrm{Fe}(\mathrm{CN})_{6}\right]$, hydrogen peroxide $\left(\mathrm{H}_{2} \mathrm{O}_{2}\right)$, hydrochloric acid, and benzoic acid were purchased from Shanghai Reagent Chemical Co. (China). 4,4,4,4-(Porphine-5,10,15,20-tetrayl)tetrakis $\left(\mathrm{H}_{2} \mathrm{TCPP}\right)$ was obtained from Innochem (China). $\mathrm{ZrOCl}_{2} \cdot 8 \mathrm{H}_{2} \mathrm{O}$ was purchased from Sigma-Aldrich (China), and polyvinylpyrrolidone (PVP) was purchased from Aladdin-Reagent Co. Ltd. (China). $\mathrm{Ru}(\mathrm{dpp})_{3} \mathrm{Cl}_{2}$ was obtained from Meryer Chemical Technology Co., Ltd. (Shanghai, China). Singlet oxygen sensor green (SOSG) was purchased from Invitrogen (USA). The membrane protein extraction kit, $2^{\prime}, 7^{\prime}-$ dichlorofluorescin diacetate (DCFH-DA), Hoechst 33342, 3-[4,5-dimethylthiazol-2-yl]-2,5-diphenyltetrazolium-bromide (MTT) and propidium iodide (PI) were provided by the Beyotime Institute of Biotechnology (China). The calcein AM and annexin V-FITC/PI apoptosis and necrosis detection kit were obtained from Yeasen (Shanghai, China). The ROS-ID hypoxia/oxidative stress detection kit was purchased from Enzo Life Sciences (Switzerland). Antibodies were purchased from Abcam (China). Dulbecco's modified Eagle's medium (DMEM), Roswell Park Memorial Institute (RPMI) 1640 medium, penicillin-streptomycin, trypsin and fetal bovine serum (FBS) were purchased Gibco Invitrogen Corp (USA). All other solvents were of analytical grade and used as received. Polycarbonate porous membrane $(400 \mathrm{~nm})$ and Avanti mini extruder were purchased from Avanti Polar Lipids (USA). The syringe pump (Lead Fluid, TYD02-02, China) was used to deliver stock solutions. The morphology of NPs was detected by a transmission electron microscopy (TEM) (JEM-2100 microscope) and a field emission scanning electron microscope (SEM) (Zeiss SIGMA). The UV-vis absorbance was measured by a UVvis spectrophotometer (Lambda Bio40, Perkin-Elmer) and fluorescence was detected by an LS55 luminescence spectrometer (Perkin-Elmer). Hydrodynamic size and zeta potential were measured by a Malvern Zetasizer Nano-ZS ZEM3600 (UK). All confocal laser microscopy images were collected by a confocal laser scanning microscopy (CLSM) (Nikon C1-Si TE2000, Japan). Fluorescence change was analyzed at cellular level by a flow cytometry (BD FACSAria ${ }^{\mathrm{TM}}$ III, USA). FL in vivo was performed on a small animal imaging system (PerkinElmer). The $660 \mathrm{~nm}$ and $808 \mathrm{~nm}$ NIR lasers (STONE Laser, China) were used for the PDT and PTT study, respectively. MTT assay was conducted on a microplate reader (BIO-RAD, Model 550, 
USA). MRI was conducted on a Bruker BioSpec $7 \mathrm{~T} /$ $20 \mathrm{~cm}$ system (Bruker, Germany). The PAI system was built by Huazhong University of Science and Technology.

\section{Preparation of PB NPs}

In all, $1.1 \mathrm{~g}$ of $\mathrm{K}_{3}\left[\mathrm{Fe}(\mathrm{CN})_{6}\right]$ and $24 \mathrm{~g}$ of PVP were dissolved in $300 \mathrm{~mL}$ of ultrapure water under sonication. Then, $270 \mu \mathrm{L}$ of hydrochloric acid was added and the mixture was stirred at room temperature for $30 \mathrm{~min}$. Next, the reaction was allowed to proceed at $80^{\circ} \mathrm{C}$ for $20 \mathrm{~h}$, and then the dark blue particles were collected by centrifugation (11,000 rpm, $15 \mathrm{~min}$ ), followed by washing with ultrapure water once and DMF three times.

\section{Controlled synthesis of core-shell PB@PCN NPs}

A syringe pump was used to separately deliver metal $\left(\mathrm{ZrOCl}_{2} \cdot 8 \mathrm{H}_{2} \mathrm{O}\right)$ and ligand (TCPP) stock solutions at a controlled feed rate into the PB solution with stirring. In detail, controllable coating of the PCN shell on the PB core was carried out at $90^{\circ} \mathrm{C}$ under atmospheric pressure in a DMF solvent system. First, $6 \mathrm{mg}$ of PB and $222 \mathrm{mg}$ of benzoic acid were dissolved in $40 \mathrm{~mL}$ of DMF in a threeneck bottle. Then, the $\mathrm{ZrOCl}_{2} \cdot 8 \mathrm{H}_{2} \mathrm{O}$ stock solution (in DMF, $\mathrm{ZrOCl}_{2} 9.1 \mathrm{mM}$ and benzoic acid $91 \mathrm{mM}$ ) and the TCPP stock solution (in DMF, $1.3 \mathrm{mM}$ ) were separately delivered into the three-neck bottle. In this process, PCN grew with $\mathrm{PB}$ as the core. The whole reaction process was carried out with stirring, and the feed rate was $0.5 \mathrm{~mL} \mathrm{~h}^{-1}$. By controlling the total feed $(0.2 \mathrm{~mL}, 0.5 \mathrm{~mL}, 1 \mathrm{~mL}$, $1.5 \mathrm{~mL}, 2 \mathrm{~mL}, 3 \mathrm{~mL}, 4 \mathrm{~mL}$, or $6 \mathrm{~mL}$ ), a series of PB@PCN NPs with different PCN shell thicknesses were obtained. Finally, the particles were collected by centrifugation and washed with DMF and ultrapure water.

\section{Preparation of CT26 tumor cell membrane fragments}

A membrane protein extraction kit was employed to extract the CT26 cell membrane. Briefly, the collected CT26 cells were dispersed in membrane protein extraction buffer solution and cooled at $4{ }^{\circ} \mathrm{C}$ for $15 \mathrm{~min}$. Next, the cell suspension underwent three repeated freeze-thaw cycles. Then, the broken cell suspension was centrifuged $\left(700 \mathrm{~g}, 10 \mathrm{~min}, 4^{\circ} \mathrm{C}\right)$ to remove the precipitate, and the supernatant was further centrifuged $(14,000 \times g, 30 \mathrm{~min})$ to obtain the precipitate.

\section{Preparation of PB@PCN@MEM}

The cell membrane coating process was conducted using an Avanti mini extruder. First, the prepared tumor cell membrane fragments and PB@PCN NPs $(\mathrm{w} / \mathrm{w}=1: 1)$ were dispersed in ultrapure water, and the mixture was extruded through a polycarbonate porous membrane $(400 \mathrm{~nm})$ using an Avanti mini extruder. Then, PB@PCN@MEM was collected by centrifugation (8000 rpm, $15 \mathrm{~min}$ ).

\section{Photothermal effects of PB@PCN}

To assess the photothermal performance, a series of concentrations $\left(5,10,20,50\right.$, and $100 \mathrm{mg} \mathrm{L}^{-1}$ in terms of $\mathrm{PB})$ of $\mathrm{PB} @ \mathrm{PCN}$ was exposed to an $808 \mathrm{~nm}$ laser $(1.0 \mathrm{~W}$ $\mathrm{cm}^{-2}$ ) for $600 \mathrm{~s}$, with real-time monitoring of the temperature and recording of the image data. Moreover, PBS, PB $\left(20 \mathrm{mg} \mathrm{L}^{-1}\right)$ and PCN $\left(10 \mathrm{mg} \mathrm{L}^{-1}\right)$ were used as the control groups for $\mathrm{PB} @ \mathrm{PCN}\left(20 \mathrm{mg} \mathrm{L}^{-1}\right.$ in terms of $\left.\mathrm{PB}\right)$. To investigate the photostability of $\mathrm{PB} @ \mathrm{PCN}$, the $\mathrm{PB} @ \mathrm{PCN}$ dispersion $\left(20 \mathrm{mg} \mathrm{L}^{-1}\right.$ in terms of $\left.\mathrm{PB}\right)$ underwent four on/off cycles of $808 \mathrm{~nm}$ laser irradiation.

\section{Detection of $\mathrm{O}_{2}$ generation in solution}

$\left[\left(\mathrm{Ru}(\mathrm{dpp})_{3}\right)\right] \mathrm{Cl}_{2}$ was used as the $\mathrm{O}_{2}$ sensing probe, the fluorescence of which was reduced by molecular oxygen. To assess the influence of the PCN shell on the PB core catalytic efficiency, PB@PCN with three different PCN shell thicknesses $\left(20 \mathrm{mg} \mathrm{L}^{-1}\right.$ in terms of $\left.\mathrm{PB}\right)$ were added to a 24-well plate with $3.0 \mathrm{wt} \% \mathrm{H}_{2} \mathrm{O}_{2}$ and $\left[\left(\mathrm{Ru}(\mathrm{dpp})_{3}\right)\right] \mathrm{Cl}_{2}$ $\left(10 \mathrm{mg} \mathrm{L}^{-1}, 10 \mu \mathrm{L}\right)$ and then incubated at $37^{\circ} \mathrm{C}$ for $15 \mathrm{~min}$. In addition, PBS, PB $\left(20 \mathrm{mg} \mathrm{L}^{-1}\right)$ and PB@PCN $3 \mathrm{~mL}+$ $808 \mathrm{~nm}$ irradiation were used as the control groups. After treatment, the fluorescence of $\left[\left(\mathrm{Ru}(\mathrm{dpp})_{3}\right)\right] \mathrm{Cl}_{2}$ was recorded by a small animal fluorescence imaging system (IVIS, $\lambda_{\mathrm{ex}}=488 \mathrm{~nm}, \lambda_{\mathrm{em}}=620 \mathrm{~nm}$ ). Furthermore, the real-time production of $\mathrm{O}_{2}$ was measured via a DOG3082 dissolved oxygen meter.

\section{Detection of ${ }^{1} \mathrm{O}_{2}$ generation in solution}

The generation of ${ }^{1} \mathrm{O}_{2}$ was monitored using a singlet oxygen sensor (SOSG) as a probe. First, the ${ }^{1} \mathrm{O}_{2}$ generation in different solutions under $660 \mathrm{~nm}$ laser irradiation were compared to verify the enhanced ${ }^{1} \mathrm{O}_{2}$ generation of PB@PCN. In simple terms, $10 \mu \mathrm{L}$ of SOSG $(500 \mu \mathrm{M}$ in DMSO) was added to $990 \mu \mathrm{L}$ of different solutions (PBS, $\mathrm{H}_{2} \mathrm{O}_{2}, \mathrm{~PB}, \mathrm{PCN}, \mathrm{PCN}+\mathrm{H}_{2} \mathrm{O}_{2}, \mathrm{~PB} @ \mathrm{PCN} 3 \mathrm{~mL}$, and $\mathrm{PB} @ \mathrm{PCN} 3 \mathrm{~mL}+\mathrm{H}_{2} \mathrm{O}_{2} 10 \mathrm{mg} \mathrm{L}^{-1}$ in terms of PCN and $\left.0.3 \% \mathrm{H}_{2} \mathrm{O}_{2}\right)$. After irradiation $\left(660 \mathrm{~nm}, 0.03 \mathrm{~W} \mathrm{~cm}^{-2}\right)$ at different times, the fluorescence of the solutions at $530 \mathrm{~nm}$ was measured. The ${ }^{1} \mathrm{O}_{2}$ generation ability was defined as $\left(I-I_{0}\right)$, where $I_{0}$ is the initial fluorescence intensity.

\section{Evaluation of intracellular $\mathrm{O}_{2}$ generation}

CT26 cells were seeded and cultured for $24 \mathrm{~h}$ in a 24-well plate at $37^{\circ} \mathrm{C}$. Then, $10 \mu \mathrm{L}$ of $\left[\left(\mathrm{Ru}(\mathrm{dpp})_{3}\right)\right] \mathrm{Cl}_{2}\left(10 \mathrm{mg} \mathrm{L}^{-1}\right)$ was added into each well. Twelve hours later, the cells were washed with PBS, and $200 \mu \mathrm{L}$ of 1640 medium was added. Then, PBS, PB or PB@PCN (final concentration: $20 \mathrm{mg} \mathrm{L}^{-1}$ in terms of $\mathrm{PB}$ ) were added to the wells and further incubated for $24 \mathrm{~h}$. After washing with PBS, the fluorescence of $\left[\left(\mathrm{Ru}(\mathrm{dpp})_{3}\right)\right] \mathrm{Cl}_{2}$ was recorded with a small animal fluorescence imaging system $\left(\lambda_{\mathrm{ex}}=488 \mathrm{~nm}, \lambda_{\mathrm{em}}=\right.$ $620 \mathrm{~nm})$. 


\section{Detection of intracellular ROS}

Intracellular ROS were measured by using DCFH-DA as the indicator. To detect intracellular ROS under normoxic conditions, CT26 cells were seeded and cultured for $24 \mathrm{~h}$ in a 6-well plate at $37^{\circ} \mathrm{C}$ in $21 \% \mathrm{O}_{2}$. Following treating CT26 cells with PBS, PB, PCN, or PB@PCN (PB $30 \mathrm{mg}$ $\mathrm{L}^{-1}$, PCN $15 \mathrm{mg} \mathrm{L}^{-1}$ ) for $6 \mathrm{~h}$, the medium was changed to the well-prepared DCFH-DA staining solution $\left(1 \times 10^{-6}\right.$ $\mathrm{M})$ and further incubated for $30 \mathrm{~min}$. Next, the cells were washed three times with PBS and treated with a 660-nm laser irradiation $\left(0.03 \mathrm{~W} \mathrm{~cm}^{-2}\right)$ for $3 \mathrm{~min}$. After the different treatments, the cells were observed by CLSM and detected by flow cytometry. All cells were cultured under normoxic conditions $\left(21 \% \mathrm{O}_{2}\right)$ throughout the process. Furthermore, we detected the intracellular ROS levels under hypoxic conditions $\left(1 \% \mathrm{O}_{2}\right)$. This operation was the same as above except that the CT26 cells were cultured under hypoxia.

\section{Detection of intracellular hypoxia}

To assess the ability of $\mathrm{PB} @ \mathrm{PCN}$ to relieve tumor intracellular hypoxia, the fluorogenic probe ROS-ID was used as a hypoxic sensor and detected by CLSM. CT26 cells were treated with PBS, PB, PB@PCN $\left(40 \mathrm{mg} \mathrm{L}^{-1}\right.$ in terms of $\mathrm{PB}$ ), or a high concentration of $\mathrm{PB} @ \mathrm{PCN}$ ( $80 \mathrm{mg} \mathrm{L}^{-1}$ in terms of $\mathrm{PB}$ ) for $6 \mathrm{~h}$, the previous medium was removed and the cells were washed with PBS twice. Then, the cells were stained with ROS-ID and Hoechst 33342 (a nuclear dye) for $30 \mathrm{~min}$. Finally, the cells were washed with PBS and observed by CLSM $\left(\lambda_{\mathrm{ex}}=543 \mathrm{~nm}\right.$, $\left.\lambda_{\mathrm{em}}=570-620 \mathrm{~nm}\right)$ and detected by flow cytometry. During the whole experiment, cells were cultured in hypoxic $\left(1 \% \mathrm{O}_{2}\right)$ and dark conditions.

\section{Evaluation of cellular HSP70 content}

CT26 cells were seeded and cultured for $24 \mathrm{~h}$ under normoxic conditions $\left(21 \% \mathrm{O}_{2}\right)$ in 6-well plates. Then, CT26 cells were incubated for $4 \mathrm{~h}$ at $37^{\circ} \mathrm{C}$ in medium containing different NPs: PBS, PCN, PB@PCN $\left(20 \mathrm{mg} \mathrm{L}^{-1}\right.$ in terms of PCN) and a high concentration of PB@PCN (30 $\mathrm{mg} \mathrm{L}^{-1}$ in terms of PCN). Subsequently, all cells were cultured at $43^{\circ} \mathrm{C}$ for $1 \mathrm{~h}$ to induce high expression of HSP70. After washing with PBS, the cells were irradiated with a 660-nm laser for $5 \mathrm{~min}$ and cultured for another 24 h. Finally, cellular HSP70 expression was analyzed by western blot analysis.

\section{Evaluation of cytotoxicity}

Cytotoxicity was evaluated by the MTT assay. CT26 cells were seeded and cultured for $24 \mathrm{~h}$ in a 96-well plate at $37^{\circ} \mathrm{C}$. Following treatment with gradient concentrations of PB, PCN, or PB@PCN for $4 \mathrm{~h}$, the medium was removed, fresh medium was added, and then CT26 cells were subjected to different light conditions (black, $808 \mathrm{~nm}$
(1.5 $\left.\mathrm{W} \mathrm{cm}^{-2}, 5 \mathrm{~min}\right), 660 \mathrm{~nm}\left(0.03 \mathrm{~W} \mathrm{~cm}^{-2}, 5 \mathrm{~min}\right)$ or $660+808 \mathrm{~nm})$. After further incubation for $24 \mathrm{~h}, 20 \mu \mathrm{L}$ of MTT (5 mg L ${ }^{-1}$ ) was added to each well and cultured for another $4 \mathrm{~h}$. Afterwards, the medium containing MTT was replaced with $150 \mu \mathrm{L}$ of DMSO. After the 96-well plates were shaken for $15 \mathrm{~min}$, the optical density (OD) was recorded at $570 \mathrm{~nm}$ on a microplate reader. The relative cell viabilities were calculated by the following formula: cell viability $(\%)=\mathrm{OD}_{\text {(sample) }} \times 100 / \mathrm{OD}_{\text {(control) }}$, where $\mathrm{OD}_{\text {(control) }}$ and $\mathrm{OD}_{\text {(sample) }}$ are the absorbance at $570 \mathrm{~nm}$ in the absence and presence of sample, respectively. All cells were cultured under normoxic conditions $\left(21 \% \mathrm{O}_{2}\right)$ throughout this process.

To verify that $\mathrm{PB} @ \mathrm{PCN}$ can overcome the hypoxic limitations of PDT, we further analyzed CT26 cytotoxicity under hypoxic conditions $\left(1 \% \mathrm{O}_{2}\right)$. The process of cell treatment was the same as above except that the cells were cultured under hypoxic conditions.

\section{Imaging in vivo}

CT26 tumor-bearing $\mathrm{BALB} / \mathrm{c}$ mice with a tumor volume of $\sim 300 \mathrm{~mm}^{3}$ were injected intravenously with PB@PCN or PB@PCN@MEM $\left(7.5 \mathrm{mg} \mathrm{kg}^{-1}\right.$ in terms of $\mathrm{PB}, 3.25 \mathrm{mg} \mathrm{kg}^{-1}$ in terms of PCN). At the scheduled time after injection $(0 \mathrm{~h}, 4 \mathrm{~h}, 8 \mathrm{~h}, 12 \mathrm{~h}, 24 \mathrm{~h}$, and $36 \mathrm{~h})$, tumor imaging was carried out with a small animal imaging system $\left(\lambda_{\mathrm{ex}}=640 \mathrm{~nm} ; \lambda_{\mathrm{em}}=680 \mathrm{~nm}\right)$. Moreover, mice were killed at $36 \mathrm{~h}$, and the main tissues and tumors were obtained. The fluorescence distribution in the main tissues and tumors at $36 \mathrm{~h}$ were recorded on a small animal imaging system. For MRI, the mice were observed at $0 \mathrm{~h}$, $2 \mathrm{~h}$, and $12 \mathrm{~h}$. For PA imaging, the tumor sites were scanned with a PA imaging system to obtain PA signals before and after injection (744 nm laser). During the imaging process, mice were anesthetized by intraperitoneal injection of $5 \%$ chloral hydrate solution. Specifically, PA imaging of blood vessels at the tumor sites in mice was conducted with a $523 \mathrm{~nm}$ laser.

\section{Antitumor study and histochemical analysis}

CT26 tumor-bearing BALB/c mice with a tumor volume of $\sim 100 \mathrm{~mm}^{3}$ were randomly divided into 6 groups (6 mice in each group): $\mathrm{PBS}, \mathrm{PBS}+, \mathrm{PB}+, \mathrm{PCN}+$, PB@PCN+, and PB@PCN@MEM+. First, $100 \mu \mathrm{L}$ of each different sample solution was injected into each group of mice via the tail vein. Twelve hours after injection, all mice except those in the PBS group were irradiated with an $808 \mathrm{~nm}$ laser $\left(1.5 \mathrm{~W} \mathrm{~cm}^{-2}\right)$ for $4 \mathrm{~min}$ and a $660-\mathrm{nm}$ laser $\left(0.22 \mathrm{~W} \mathrm{~cm}^{-2}\right)$ for $4 \mathrm{~min}$. During treatment, the tumor sizes and body weights were recorded daily. The tumor volume (V) was calculated according to the following formula: $V=0.5 \times L \times W^{2}$, where $L$ and $W$ represent the shortest and longest diameter of the tumors, respectively. On day 14, all mice were killed, and the 
tumors were excised, weighed, photographed, and collected for histological analysis. In addition, the main organs (hearts, livers, spleens, lungs, and kidneys) were dissected and collected for histological analysis.

\section{In vivo pharmacokinetics study}

The pharmacokinetics of PB@PCN and PB@PCN@MEM were investigated using CT26 tumorbearing mice with a tumor volume of $\sim 200 \mathrm{~mm}^{3}$. CT26 tumor-bearing mice were randomly divided into two groups with 3 mice in each group. One group was injected intravenously with $\mathrm{PB} @ \mathrm{PCN} @ \mathrm{MEM}$, and the other group was injected intravenously with $\mathrm{PB} @ \mathrm{PCN}$ (both $7.5 \mathrm{mg} \mathrm{kg}^{-1}$ in terms of $\left.\mathrm{PB}\right)$. Blood samples $(10 \mu \mathrm{L})$ were extracted from the mouse tail veins at the scheduled time $(0.5 \mathrm{~h}, 1 \mathrm{~h}, 2 \mathrm{~h}, 4 \mathrm{~h}, 8 \mathrm{~h}$, and $24 \mathrm{~h})$ and added to $490 \mu \mathrm{L}$ of ultrapure water. Next, the solutions were subjected to ultrasound to obtain transparent solutions, and the NP concentrations were determined using an LS55 luminescence spectrometer. $\left(\lambda_{\mathrm{ex}}=420 \mathrm{~nm}, \lambda_{\mathrm{em}}=650 \mathrm{~nm}\right)$.

\section{Blood biochemistry and routine blood examination}

$\mathrm{BALB} / \mathrm{C}$ mice were randomly divided into four groups of five mice and intravenously injected with $200 \mu \mathrm{L}$ of PBS, PB, PB@PCN or PB@PCN@MEM solution (15 mg $\mathrm{kg}^{-1}$ in terms of $\mathrm{PB}$ ). After 3 days, blood samples were collected in anticoagulation tubes via cardiac puncture and then analyzed by a blood biochemistry analyzer (MNCHIP Pointcare) and an auto hematology analyzer (MC-6200VET).

\section{PDT in vivo}

When the tumor volume reached $\sim 200 \mathrm{~mm}^{3}$, a mixture of SOSG $\left(50 \times 10^{-6} \mathrm{M}, 25 \mu \mathrm{L}\right), \mathrm{PB}(25 \mu \mathrm{L}), \mathrm{PCN}(25 \mu \mathrm{L})$, PB@PCN $(25 \mu \mathrm{L})$, or PB@PCN@MEM $(25 \mu \mathrm{L})$ was directly injected into the tumors. The final concentration of TCPP was $25 \mathrm{mg} / \mathrm{L}$. After $2 \mathrm{~h}$, laser irradiation $(660 \mathrm{~nm}$, $0.22 \mathrm{~W} \mathrm{~cm}^{-2}$ ) was performed on each group for $4 \mathrm{~min}$. Then, all the tumors were harvested and frozen-sectioned for examination.

\section{In vivo hypoxia-inducible factor $a$ detection}

When the tumor volume reached $\sim 200 \mathrm{~mm}^{3}$, different samples were directly injected into the tumors. After $24 \mathrm{~h}$, all mice were killed, and the tumors were collected for hypoxia-inducible factor $\alpha$ (HIF- $\alpha$ ) immunohistochemical staining.

\section{In vivo HSP70 detection}

When the tumor volume reached $\sim 200 \mathrm{~mm}^{3}$, different samples were injected into the mice via the tail vein. After $12 \mathrm{~h}$, all mice were subjected to an $808 \mathrm{~nm}$ laser (1.5 W $\left.\mathrm{cm}^{-2}\right)$ for $4 \mathrm{~min}$ and a 660 -nm laser $\left(0.22 \mathrm{~W} \mathrm{~cm}^{-2}\right)$ for $4 \mathrm{~min}$. After another $24 \mathrm{~h}$, all mice were killed, and the tumors were collected for HSP70 immunohistochemical staining.

\section{Statistical analysis}

Significant differences were calculated via the two-tailed $T$-test. Statistical significance was noted as follows: ${ }^{*} p<$ $0.05,{ }^{* * *} p<0.01,{ }^{* * * * *} p<0.001$.

\section{Results and discussion \\ Controlled synthesis of PB@PCN}

The process for the controllable synthesis of the PB@PCN nanohybrid is depicted in Fig. 1a. PB was first prepared via the one-pot method, and TEM (Fig. 1b) and SEM (Fig. S1) images of PB showed a monodisperse cube with a particle size of approximately $110 \mathrm{~nm}$. The controlled synthesis of $\mathrm{PB} @ \mathrm{PCN}$ was achieved with the use of a syringe pump. Metal ion ( $\mathrm{Zr}$ ) and porphyrin (TCPP) ligand stock solutions were separately delivered into the $\mathrm{PB}$ solution under a controlled feed rate with stirring. By controlling the feed rate, the concentration of ligands in the reaction solution was controlled below the critical nucleation concentration of PCN to prevent the generation of the PCN nucleus, which was crucial for the growth of PCN with PB as the crystal nucleus. If the feeding speed was too fast (Fig. S2), the PCN nucleus would be generated in the reaction solution, and $\mathrm{PCN}$ would not grow with $\mathrm{PB}$ as the crystal nucleus. When the feeding speed was lower than the critical speed, $\mathrm{PCN}$ grew with $\mathrm{PB}$ as the nucleus. As a consequence, by controlling the amount of the feed, a series of PB@PCN nanohybrids with different PCN shell thicknesses were obtained, and the thickness of the PCN shell increased with the addition of ligands, as confirmed by the TEM and SEM images of PB@PCN (Fig. 1b, Fig. S1). The hydrodynamic size of $\mathrm{PB} @ \mathrm{PCN}$ increased gradually with increasing shell thickness (Fig. 1c), and as displayed in Table S1, with increasing PCN shell thickness, the size obtained from the TEM images gradually increased from $110 \mathrm{~nm}$ to $140 \mathrm{~nm}$. The crystal phases of PB@PCN and PB were further confirmed by powder X-ray diffraction (PXRD) (Fig. S3). Then, the optical properties of the $\mathrm{PB} @ \mathrm{PCN}$ series were investigated by UV-vis and fluorescence spectroscopy. As shown in Fig. S4, PB@PCN had similar characteristic absorption peaks to those of $\mathrm{PB}$ at $720 \mathrm{~nm}$ and the same absorption peaks as PCN at 422, 518, 550 , and $650 \mathrm{~nm}$. As expected, as the PCN shell thickness increased, the characteristic absorption peaks shared with PCN were enhanced (Fig. 1d). Due to Förster resonance energy transfer (FRET) between $\mathrm{PCN}$ and $\mathrm{PB}$, it was not surprising to observe the obvious fluorescence quenching of PB@PCN compared with that of PCN (Fig. S5).

\section{Tumor cell membrane camouflage}

Subsequently, to endow PB@PCN with good immune evasion and an active targeting ability, the CT26 tumor cell 


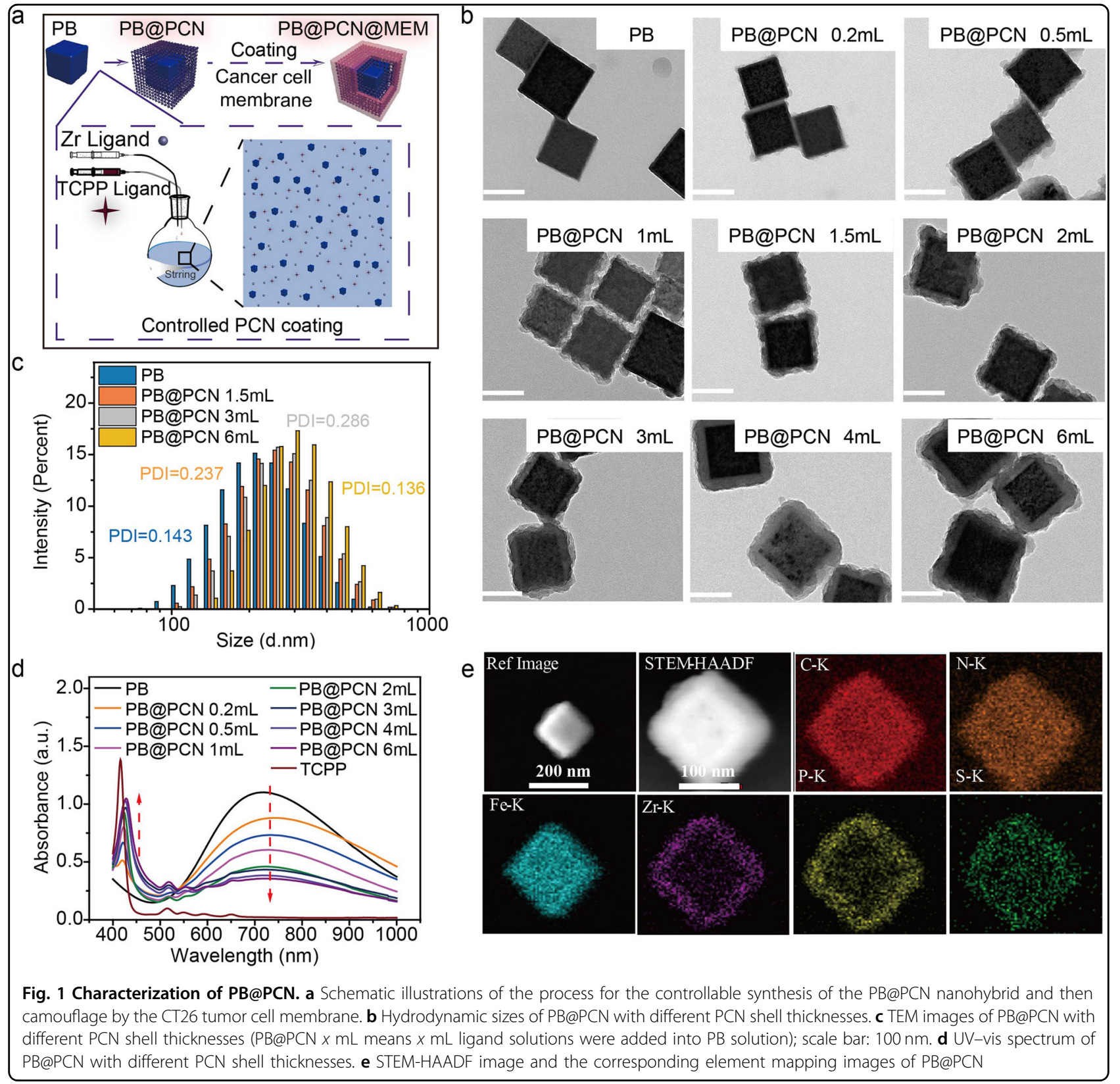

membrane was used to modify the surface of the NPs (PB@PCN@MEM). In Fig. S6, the TEM image of PB@PCN@MEM showed an uneven translucent layer around PB@PCN, which was thought to be cell membrane fragments. Comparing the hydrodynamic size and zeta potential of PB@PCN@MEM with those of PB@PCN (Table S2), coating of the cell membrane was further indicated Furthermore, to obtain more convincing evidence to demonstrate the successful coating with the tumor cell membrane, the protein ingredients of PB@PCN@MEM were analyzed using sodium dodecyl sulfate-polyacrylamide gel electrophoresis (SDS-PAGE, Fig. S7), and it was displayed that the tumor cell membrane proteins were extensively retained. Moreover, the multilayered structure of PB@PCN@MEM was detected by TEM mapping (Fig. 1e), and the distribution of the characteristic elements from inside to outside (Fe corresponding to $\mathrm{PB}, \mathrm{Zr}$ to $\mathrm{PCN}, \mathrm{P}$ and $\mathrm{S}$ to cell membrane) were very clear. In addition, infrared spectroscopy (FITC) further confirmed the multicomponent structure (Fig. S8). Finally, the PCN NPs were synthesized via a one-pot method and detected by SEM (Fig. S9).

\section{Photothermal behavior, $\mathrm{O}_{2}$ generation and enhanced ${ }^{1} \mathrm{O}_{2}$ generation in solution}

Because shell thickness affects the diffusion rate of small molecules (such as $\mathrm{O}_{2}, \mathrm{H}_{2} \mathrm{O}_{2}$, and $\mathrm{H}_{2} \mathrm{O}$ ) and PS loading, 
we speculated that the shell thickness had a great impact on the performance of the core-shell nanohybrid. An too thick shell would limit $\mathrm{H}_{2} \mathrm{O}_{2}$ contact with the PB core, but a too thin PCN shell would reduce PS loading and cause $\mathrm{O}_{2}$ to diffuse too quickly to be well utilized by PS, thus limiting the photodynamic effect. To select the PB@PCN nanohybrid with the optimal shell thickness, the abilities of the PB@PCN with different shell thicknesses to conduct photothermal $\mathrm{O}_{2}$ generation and enhanced ${ }^{1} \mathrm{O}_{2}$ were compared in solution. The mechanism of $\mathrm{PB} @ \mathrm{PCN}$ nanohybrid-mediated photothermal $\mathrm{O}_{2}$ generation and enhanced PDT is shown in Fig. 2a. To evaluate the photothermal effects of $\mathrm{PB} @ \mathrm{PCN}$, the temperature changes were recorded under $808 \mathrm{~nm}$ irradiation. As shown in Figs. S10 and S11, the PB@PCN solution temperature rose from 32 to $57^{\circ} \mathrm{C}$ upon irradiation for $10 \mathrm{~min}$, and $\mathrm{PB} @ \mathrm{PCN}$ maintained excellent photothermal conversion properties during four heating-cooling cycles. In addition, PB@PCN possessed a similar photothermal conversion ability as PB, which demonstrated that the PCN shell had little effect on the photothermal properties of the core (Fig. 2b). Furthermore, the photothermal effects of $\mathrm{PB} @ \mathrm{PCN}$ aqueous dispersions at various concentrations was detected, proving high concentrations corresponded to fast heating rates and high peak temperatures (Fig. 2c).

Subsequently, the catalase-like activity of PB@PCN catalyzing $\mathrm{H}_{2} \mathrm{O}_{2}$ to produce $\mathrm{O}_{2}$ was evaluated. As shown in Fig. S12, after mixed solutions of PB (PB or PB@PCN with different shell thicknesses) and diluted $\mathrm{H}_{2} \mathrm{O}_{2}$ were incubated at $37^{\circ} \mathrm{C}$ for $15 \mathrm{~min}$, obvious bubbles were observed, while negligible bubbles were found in the PBS and PCN groups. To study the effect of the $\mathrm{H}_{2} \mathrm{O}_{2}$ concentration on $\mathrm{PB} @ \mathrm{PCN}$-catalyzed $\mathrm{O}_{2}$ generation, the $\mathrm{O}_{2}$ levels in PB@PCN suspensions with different $\mathrm{H}_{2} \mathrm{O}_{2}$ concentrations were compared. Compared with the group without $\mathrm{H}_{2} \mathrm{O}_{2}$, the $\mathrm{O}_{2}$ levels in the groups with $\mathrm{H}_{2} \mathrm{O}_{2}$ increased significantly, and higher $\mathrm{H}_{2} \mathrm{O}_{2}$ concentration with higher oxygen concentration presented as the reduced fluorescence intensity of the $\mathrm{O}_{2}$ probe ([Ru $\left.(\mathrm{dpp})_{3}\right] \mathrm{Cl}_{2}$ ) (Fig. 2d, Fig. S13). To investigate the effects of the PCN shell thickness and photothermal effects on oxygen generation efficiency, both an $\mathrm{O}_{2}$ probe and a dissolved oxygen meter were used (Fig. 2e, f). They both demonstrated that the oxygen production efficiency was impeded by a PCN shell that was too thick (PB@PCN $6 \mathrm{~mL}$ ) and was improved by photothermal treatment. We speculated that this result was caused by the PCN shell being too thick and limiting the diffusion of $\mathrm{O}_{2}$ and $\mathrm{H}_{2} \mathrm{O}_{2}$ instead of the thermal effect accelerating the decomposition of $\mathrm{H}_{2} \mathrm{O}_{2}$.

Finally, the ${ }^{1} \mathrm{O}_{2}$ production capacity of $\mathrm{PB} @ \mathrm{PCN}$ was evaluated by the SOSG (a ${ }^{1} \mathrm{O}_{2}$ probe). As shown in Fig. $2 \mathrm{~g}$, the fluorescence of SOSG was enhanced upon treatment with $\mathrm{PB} @ \mathrm{PCN}$ under $660 \mathrm{~nm}$ light irradiation, indicating the excellent ability of $\mathrm{PB} @ \mathrm{PCN}$ to produce ${ }^{1} \mathrm{O}_{2}$. As shown in Fig. 2h, the presence of $\mathrm{H}_{2} \mathrm{O}_{2}$ made no difference in the ${ }^{1} \mathrm{O}_{2}$ generation capacity of $\mathrm{PCN}$, while $\mathrm{H}_{2} \mathrm{O}_{2}$ could observably enhance the ${ }^{1} \mathrm{O}_{2}$ generation capacity of $\mathrm{PB} \mathrm{PCN}$. The above result was ascribed to the catalaselike activity of the $\mathrm{PB}$ core that catalyzed $\mathrm{H}_{2} \mathrm{O}_{2}$ to produce $\mathrm{O}_{2}$, and this increase in $\mathrm{O}_{2}$ is beneficial for enhanced PDT. The ${ }^{1} \mathrm{O}_{2}$ generation capacity of $\mathrm{PB} @ P C N$ was obviously stronger than that of PCN in the absence of $\mathrm{H}_{2} \mathrm{O}_{2}$, which was possibly caused by the conjugated structure of the PB core that enhanced the light absorption and energy conversion efficiency of the PCN shell. In view of the too thick PCN shell bringing down the efficiency of $\mathrm{O}_{2}$ generation, the ${ }^{1} \mathrm{O}_{2}$ generation capacity of $\mathrm{PB} @ \mathrm{PCN}$ with different shell thicknesses in the presence of $\mathrm{H}_{2} \mathrm{O}_{2}$ was studied. As shown in Fig. 2i, compared to the other two groups, the ${ }^{1} \mathrm{O}_{2}$ generation efficiency in the $\mathrm{PB} \mathrm{PCN} 6 \mathrm{~mL}$ group was obviously lower, which decreased the $\mathrm{O}_{2}$-dependent ${ }^{1} \mathrm{O}_{2}$ generation. However, PCN shells that are too thin would cause $\mathrm{O}_{2}$ to diffuse too quickly to be well utilized by PS, thus limiting ${ }^{1} \mathrm{O}_{2}$ generation, just as the ${ }^{1} \mathrm{O}_{2}$ generation efficiency in the PB@PCN $3 \mathrm{~mL}$ group was higher than that of the PB@PCN $0.5 \mathrm{~mL}$ group. Thus, to comprehensively conclude the above results, PB@PCN $3 \mathrm{~mL}$ had an optimal shell thickness for combined PTT/PDT therapy, which provided the best core-shell nanohybrid structure for the following experiments in vitro and in vivo. (In the subsequent studies, PB@PCN stands for PB@PCN 3 mL.)

We further studied the effect of cell membrane coating on the efficiency of heat and $\mathrm{O}_{2}$ generation. As shown in Fig. S14, PB@PCN@MEM and PB@PCN showed similar photothermal effects, demonstrating that the cell membrane coating had a negligible effect on the efficiency of heat generation. In contrast, as shown in Fig. S14, PB@PCN@MEM was less efficient than PB@PCN for $\mathrm{O}_{2}$ generation, illustrating that cell membrane coating weakens the $\mathrm{O}_{2}$ generation ability of NPs. This result was attributed to the cell membrane coating limiting the contact between $\mathrm{H}_{2} \mathrm{O}_{2}$ and the $\mathrm{PB}$ core. However, the effect on $\mathrm{O}_{2}$ generation was limited because the cell membranes were loosely and only partially coated on the NPs.

\section{${ }^{1} \mathrm{O}_{2}$ generation under normoxic and hypoxic conditions in vitro}

The hypoxic TME is responsible for the limited therapeutic effect of PDT for solid tumors, as $\mathrm{O}_{2}$ is an essential element for PDT. Considering the higher level of $\mathrm{H}_{2} \mathrm{O}_{2}$ in the TME (100 $\mu \mathrm{M}$ to $1 \mathrm{mM}$ ) compared with that in normal tissues ${ }^{38}$, we then assessed the catalase-like activity of $\mathrm{PB} @ \mathrm{PCN}$ using $\left[\mathrm{Ru}(\mathrm{dpp})_{3}\right] \mathrm{Cl}_{2}$ to measure the intracellular $\mathrm{O}_{2}$ level. Compared with the control groups (PBS and PCN), the $\mathrm{O}_{2}$ level visibly increased when 

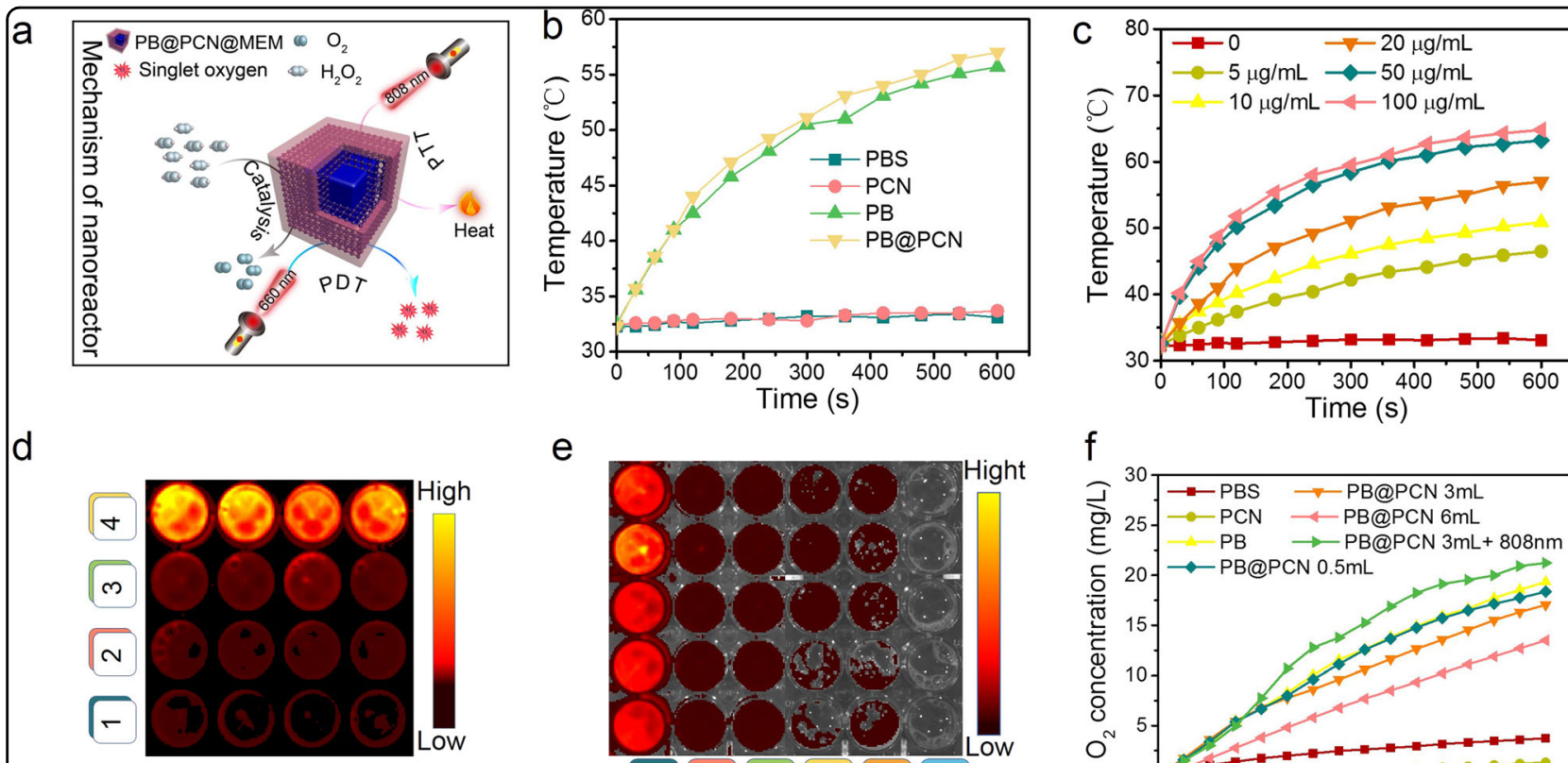

e

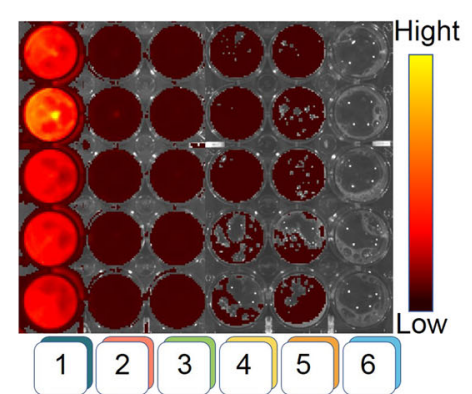

$\mathrm{h}$

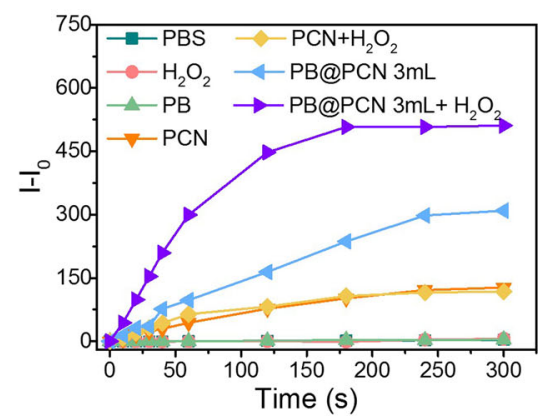

f

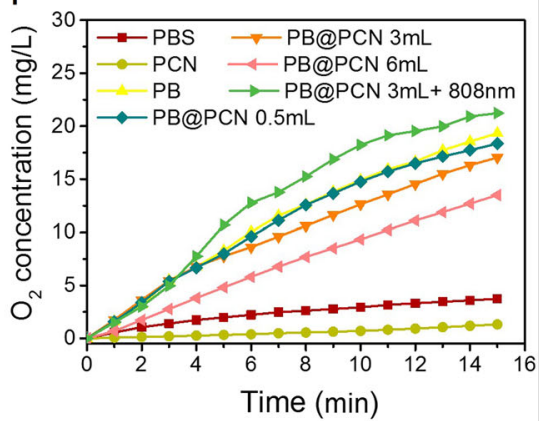

i

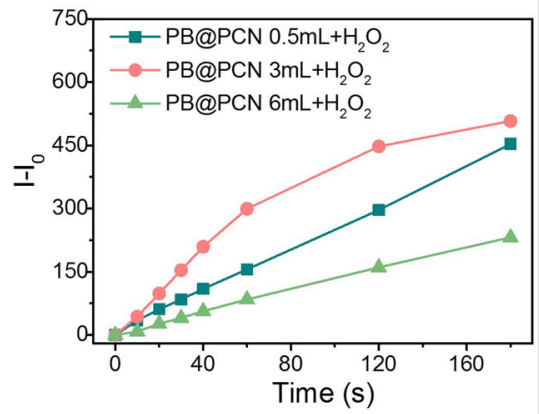

Fig. 2 Study on the photothermal, $\mathrm{O}_{2}$ generation and enhanced ${ }^{1} \mathrm{O}_{2}$ generation in solution. a Schematic illustration of PB@PCN-mediated photothermal $\mathrm{O}_{2}$ generation and enhanced PDT. $\mathbf{b}$ Temperature change as a function of time in the PBS, PCN, PB, and PB@PCN solutions irradiated with constant $808 \mathrm{~nm}$ laser power, and c PB@PCN solutions at different concentrations. d Detection of PB@PCN-catalyzed $\mathrm{O}_{2}$ generation with different concentrations of $\mathrm{H}_{2} \mathrm{O}_{2}(0(1), 1.5 \mathrm{w} \%(2), 3 \mathrm{w} \%(3)$, and $6 \mathrm{w} \%(4))$ by $\left(\left[\mathrm{Ru}(\mathrm{dpp})_{3}\right] \mathrm{Cl}_{2}\right)$. e Detection of $\mathrm{O}_{2}$ generation in different solutions (PBS (1), PB@PCN 6 mL (2), PB@PCN 3 mL (3), PB@PCN 0.5 mL (4), PB (5), and PB@PCN 3 mL + 808 nm (6)). f Detection of $\mathrm{O}_{2}$ generation using a dissolved oxygen meter. $\mathbf{g}$ Fluorescence response of SOSG upon treatment with PB@PCN irradiated with $808 \mathrm{~nm}$. $\mathbf{h}$ ROS generation under $660 \mathrm{~nm}$ light in different solutions. $\mathbf{i}^{1} \mathrm{O}_{2}$ production efficiency of PB@PCN with different PCN shell thicknesses

incubated with PB and PB@PCN (Fig. 3a, Fig. S15). In view of the above results, with great expectations, the ${ }^{1} \mathrm{O}_{2}$ generation performance of $\mathrm{PB} @ \mathrm{PCN}$ in a $1 \% \mathrm{O}_{2}$ atmosphere that mimics the hypoxic environment was stu$\operatorname{died}^{33}$. As shown in Fig. 3b by flow analysis, after incubation with PBS, PCN and PB@PCN and then irradiation with a $660 \mathrm{~nm}$ laser, the fluorescence intensity of the CT26 cells in the PB@PCN group was nearly 23 greater than that of the control group, but the $\mathrm{PCN}$ group was only two times greater than that of the control group, implying that $\mathrm{PB} @ \mathrm{PCN}$ could overcome the hypoxic limitations of PDT to a certain extent. Accordingly, the PDT efficiency of PB@PCN and PCN were evaluated in the simulated hypoxic environment ( $1 \% \mathrm{O}_{2}$ atmosphere). As illustrated in Fig. 3d, PB@PCN had a significantly higher cytotoxicity (nearly $40 \%$ ) than PCN (nearly 12\%) under hypoxic conditions. It was confirmed that hypoxia greatly weakened the effect of $\mathrm{O}_{2}$-dependent PDT, yet $\mathrm{PB} @ \mathrm{PCN}$ could effectively relieve hypoxia by triggering the decomposition of $\mathrm{H}_{2} \mathrm{O}_{2}$ to produce $\mathrm{O}_{2}$. Furthermore, to obtain more convincing evidence, ROS-ID was used as a fluorogenic probe for intracellular hypoxia evaluation and was detected by CLSM. As shown in Fig. 3c, PB and $\mathrm{PB} @ \mathrm{PCN}$ could effectively alleviate the anoxic environment in CT26 cells incubated in a $1 \% \mathrm{O}_{2}$ atmosphere, and the higher the concentration of PB@PCN (HPB@PCN), 

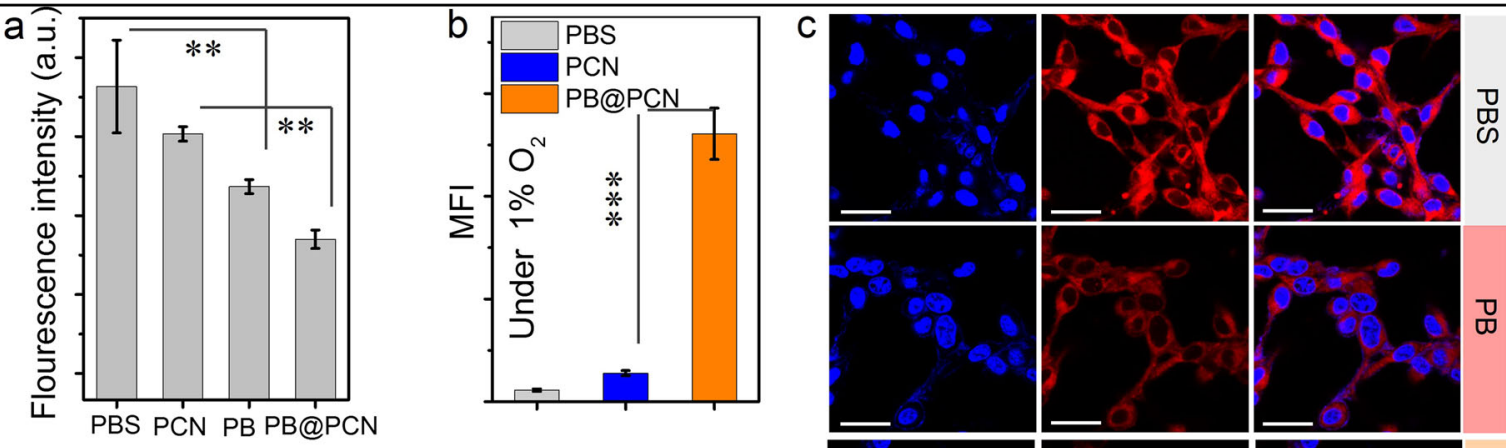

d
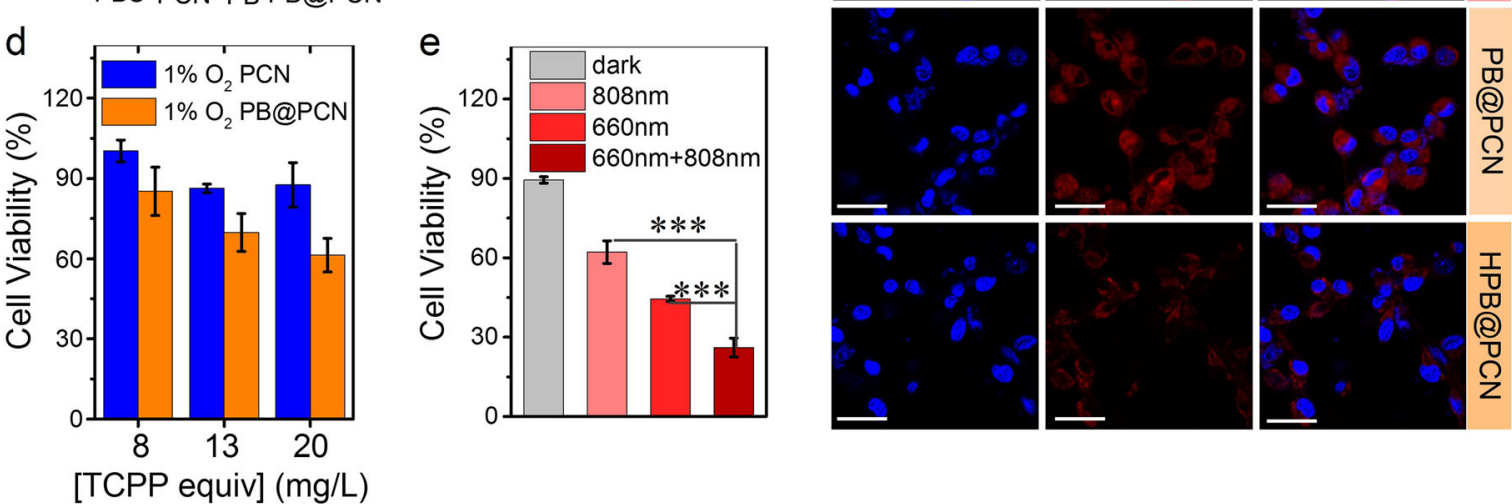

$f$

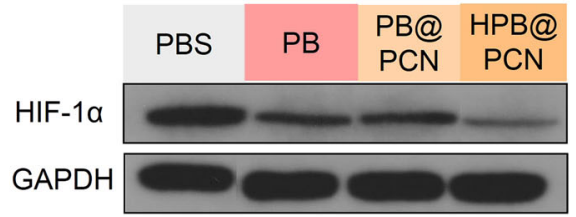

g

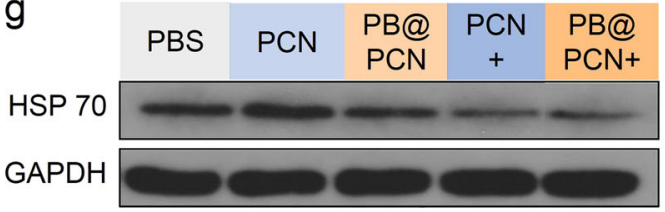

Fig. 3 Study on cytotoxicity and ${ }^{1} \mathrm{O}_{2}$ generation in vitro. a Mean fluorescence intensity (MFI) values of $\left[\mathrm{Ru}(\mathrm{dpp})_{3}\right] \mathrm{Cl}_{2}$ in cells. b Intracellular ROS detection with $660 \mathrm{~nm}$ irradiation under hypoxia by flow analysis. c CLSM images of intracellular hypoxia levels under $1 \% \mathrm{O}_{2}$ with different treatments (blue, fluorescence of Hoechst 33342; red, fluorescence of ROS-ID hypoxia probe; overlay images). $\mathbf{d}$ Under hypoxia, viability of CT26 cells incubated with $660 \mathrm{~nm}$ irradiation. e Under normoxia, relative CT26 cell viabilities (PB $18 \mathrm{mg} \mathrm{L}^{-1}, \mathrm{PCN} 9 \mathrm{mg} \mathrm{L}^{-1}$ ). f Western blot demonstrating the HIF-a level and $\mathbf{g}$ the HSP level after various treatments (+ indicates the addition of $660 \mathrm{~nm}$ irradiation; HPB@PCN indicates the high concentration of PB@PCN). (Results are expressed as the mean \pm SD of at least three independent experiments measured in triplicate. ${ }^{*} p<0.05,{ }^{* *} p<0.01$, ${ }^{* * *} p<0.001$. Scale bar: $40 \mu \mathrm{m})$

the more obvious the effect of alleviation. In addition, this result was also obtained by flow cytometry analysis (Fig. S16).

Then, we further investigated the effects of $\mathrm{PB}, \mathrm{PCN}$, and $\mathrm{PB} @ \mathrm{PCN}$ on the intracellular reactive oxygen (ROS) levels under $660 \mathrm{~nm}$ light irradiation using DCFH-DA (a ROS probe that emits green fluorescence after oxidation by ROS). Notably, the green fluorescence of the PBS, PCN, and PB@PCN groups was enhanced successively (Fig. S17). This phenomenon, ascribed to TCPP transferring light energy to $\mathrm{O}_{2}$, increased intracellular ROS levels directly, and $\mathrm{PB} @ \mathrm{PCN}$ could effectively trigger the production of $\mathrm{O}_{2}$ from $\mathrm{H}_{2} \mathrm{O}_{2}$ to elevate photoinduced ${ }^{1} \mathrm{O}_{2}$ generation. However, it cannot be ignored that the green fluorescence of the PB group was obviously weaker than that of the PBS group, and this result can mainly be attributed to the $\mathrm{H}_{2} \mathrm{O}_{2}$ consumption by $\mathrm{PB}$ catalytic decomposition. To obtain more convincing evidence, CT26 cells were treated with different samples and analyzed by flow cytometry using DCFH-DA as a probe. We obtained consistent results without (Fig. S18) or with (Fig. S19) $660 \mathrm{~nm}$ laser irradiation.

\section{Combined PTT/PDT therapy in vitro}

Then, the in vitro combined PTT/PDT therapy effects of $\mathrm{PB} @ \mathrm{PCN}$ were investigated. First, the relative viabilities of CT26, murine embryonic fibroblast (3T3) and murine macrophage (RAW264.7) cells were evaluated by the MTT assay in the dark treated with PB, PCN, PB@PCN, and PB@PCN@MEM at different concentrations for $24 \mathrm{~h}$. According to Fig. S20, the relative viabilities of all three cells remained over $90 \%$ even after incubation with high concentrations of the NPs, indicating good biocompatibility for hybrid NPs (PB@PCN and PB@PCN@MEM) 
and their components ( $\mathrm{PB}$ and $\mathrm{PCN}$ ) in the absence of light. Furthermore, considering the PDT-enhancing ability and good photothermal conversion effects of PB@PCN, the effects of PB@PCN on CT26 cell viability under different light conditions were studied (Fig. S21). First, after incubation with different NPs for $4 \mathrm{~h}$, CT26 cells were treated with $808 \mathrm{~nm}$ or $660 \mathrm{~nm}$ light. Compared to PB (under $808 \mathrm{~nm}$ irradiation) and PCN (under $660 \mathrm{~nm}$ irradiation), $\mathrm{PB} @ \mathrm{PCN}$ showed slightly more cytotoxicity against CT26 cells, which demonstrated that PB@PCN had good PDT and PTT effects under a single light. The decreased cell viability effects under single-light irradiation resulted from catalytic $\mathrm{O}_{2}$ generation-enhanced PDT and the redshift of PB absorption by PCN shell-enhanced PTT. Second, in view of the above results, we had high expectations for PB@PCN for efficient combined PTT/ PDT therapy. As expected, under $660+808 \mathrm{~nm}$ laser irradiation, compared with $\mathrm{PB}$ and PCN, PB@PCN presented obviously higher cytotoxicity. To further verify that combined PTT/PDT therapy could effectively improve the killing effects of PB@PCN on CT26 cells, the cytotoxicity of $\mathrm{PB} @ \mathrm{PCN}$ against CT26 cells under different light irradiation conditions were compared. As shown in Fig. 3e, the survival rate of cells treated with the dual laser $(660+808 \mathrm{~nm})$ was apparently lower than that of the cells treated with a single laser $(660 \mathrm{~nm}$ or $808 \mathrm{~nm})$; this result was exactly as expected. Additionally, flow cytometry with the dual fluorescence of annexin V-FITC/PI (Fig. S22) and fluorescence live/dead cell staining (Fig. S23) was performed, providing more sufficient proof for efficient combination of PTT/PDT.

\section{Expression of HIF- $a$ and HSP70 in vitro}

We further analyzed the expression of HIF- $\alpha$, which is overexpressed in hypoxic environments, after PBS, PB, and $\mathrm{PB} @ \mathrm{PCN}$ treatments in a $1 \% \mathrm{O}_{2}$ atmosphere. As shown in Fig. 3f, Fig. S24, a marked decrease in HIF- $\alpha$ was observed after PB and PB@PCN treatment in the hypoxic environment, and a more significant decrease was observed after treatment with high concentrations of $\mathrm{PB} @ \mathrm{PCN}$. This result was consistent with the above results, and we concluded that $\mathrm{PB} @ \mathrm{PCN}$ could regulate the hypoxic TME. As numerous studies have reported, HSPs are a molecular chaperone able to repair heatdenatured proteins, and their expression increases significantly upon exposure to hyperthermia to resist heatinduced apoptosis and affect the efficacy of PTT. As ROS are capable of attacking HSPs, producing ROS may be beneficial to overcome HSP-dependent tumor resistance and improve PTT efficacy. Based on this expectation, we examined the level of HSP70 in CT26 cells with different treatments via Western blotting (Fig. 3g, Fig. S24) to evaluate the impact of ROS production on the expression of HSP70. First, CT26 cells were incubated with PBS,
$\mathrm{PCN}$, and PB@PCN at $37^{\circ} \mathrm{C}$ for $4 \mathrm{~h}$ and cultured for another hour at $43^{\circ} \mathrm{C}$ to induce high expression levels of HSP70. Afterwards, $\mathrm{PCN}+$ and $\mathrm{PB} @ \mathrm{PCN}+$ were irradiated with a 660-nm laser to trigger ROS production. Compared with the cells in the absence of light, cells irradiated with light showed lower HSP70 expression levels, indicating that photoinduced ROS reduced the HSP70 content in cells.

\section{Homotypic target and immune escape of PB@PCN@MEM}

To prove the tumor cell self-recognition of PB@PCN@MEM by homologous tumor cells, the cellular internalization of PB@PCN and PB@PCN@MEM was studied by incubating the two NPs with two different cell lines, CT26 and the nontumor cell line 3T3, followed by quantitative analysis by flow cytometry (Fig. 4a, b). As we expected, in CT26 cells, the PCN fluorescence intensity of $\mathrm{PB} @ \mathrm{PCN} @ M E M$ was significantly higher than that of PB@PCN. In 3T3 cells, the TCPP fluorescence intensity of PB@PCN@MEM was slightly lower than that of $\mathrm{PB} @ \mathrm{PCN}$. This result was attributed to the decrease in the surface charge of the NPs after cell membrane coating; thus, 3T3 cells endocytosis decreased. However, since the effects of homology targeting are stronger than that of surface charge change, CT26 cells endocytosis increased. To obtain a visible result, the study of cellular internalization of the NPs was conducted with CLSM, and a consistent result was confirmed (Fig. 4c, Fig. S25). In addition, it cannot be ignored that the cell membrane coating decreased the endocytosis of the NPs into the immune cells due to the specific protein and increased negative surface charge. The immune-evading ability of PB@PCN@MEM was first examined through antiphagocytosis against murine macrophages (RAW264.7). PB@PCN without the membrane coating was used for comparison. An obvious difference was found, and PB@PCN exhibited a 2-fold greater uptake by RAW264.7 cells than PB@PCN@MEN as determined by flow cytometry (Fig. 4a, b), demonstrating the good immune escapability of PB@PCN@MEM. In addition, the influence on cytotoxicity of the tumor membrane coating against CT26 and 3T3 cells was assessed by MTT assay (Fig. 4d). As predicted, compared with PB@PCN, PB@PCN@MEM showed higher cytotoxicity against CT26 cells, but lower cytotoxicity against 3T3 cells. The above results demonstrated that the tumor cell membrane coatings gave the NPs an inherent self-targeting ability. Finally, the blood retention of PB@PCN@MEM with the CT26 cell membrane coating was measured, and bare $\mathrm{PB} @ \mathrm{PCN}$ was used as a control. As shown in Fig. 4e, PB@PCN@MEM cleared more slowly than PB@PCN from the blood, proving that this coating promoted the longer circulation of PB@PCN@MEM, which was conducive to better enrichment of the NPs at the tumor site. 


\section{a}

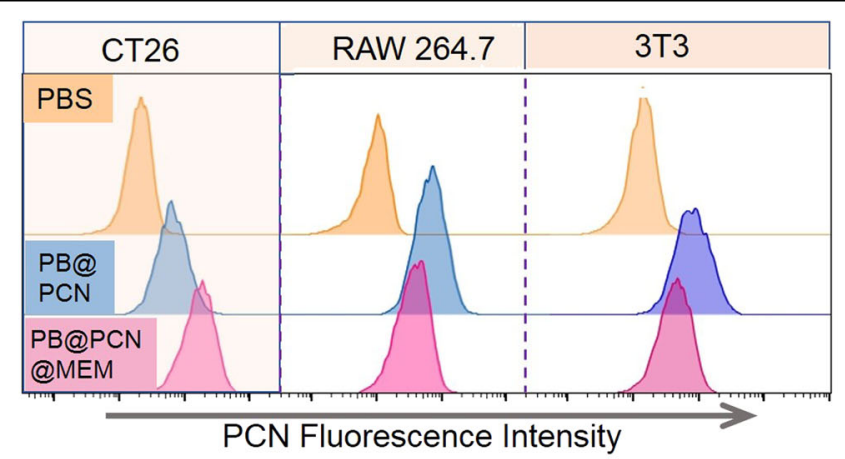

C

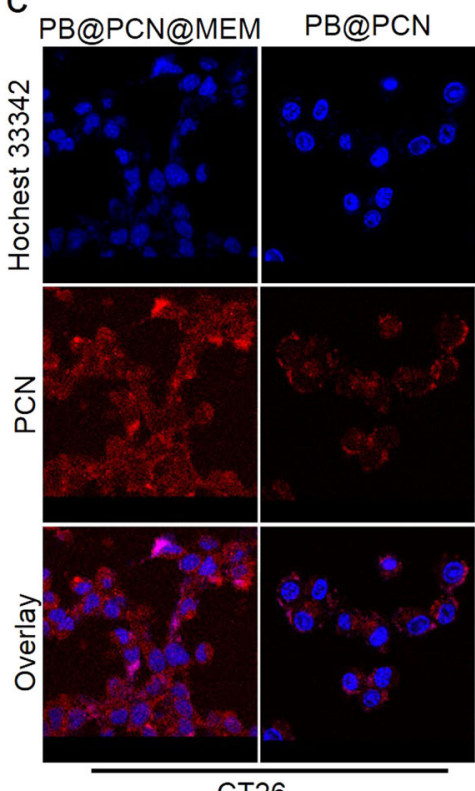

PB@PCN@MEM PB@PCN
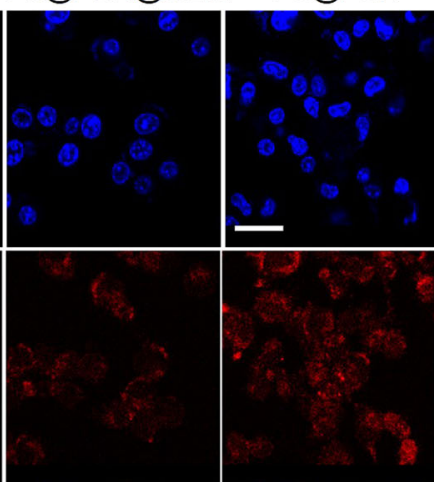

CT26

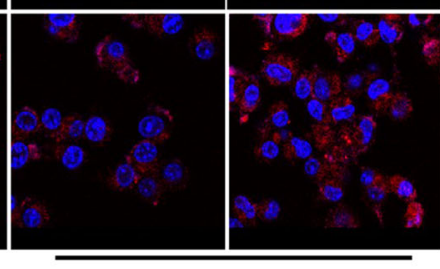

3T3 b

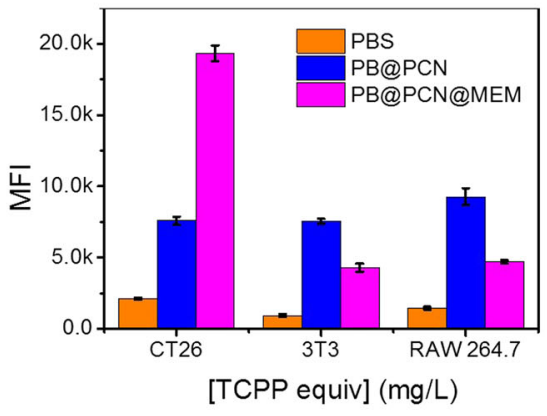

d
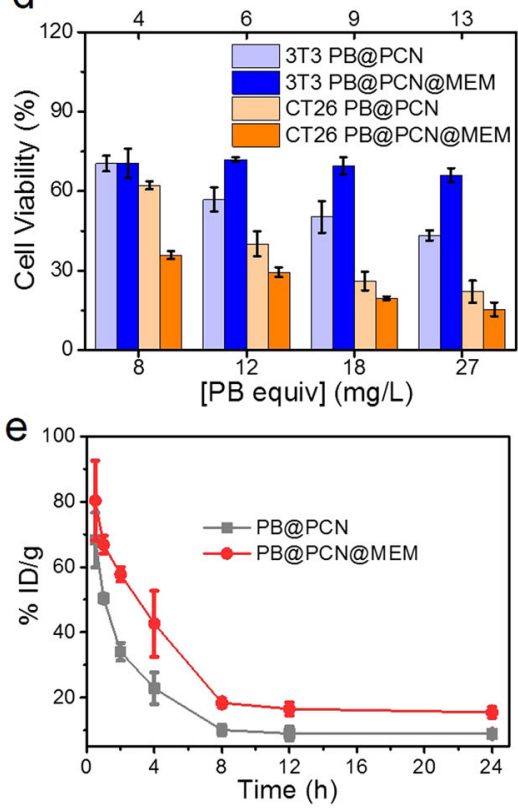

Fig. 4 Homotypic target and immune escape of PB@PCN@MEM. a Flow cytometry analysis of CT26, RAW 264.7 and 3 T3 cells endocytosis and b corresponding mean fluorescence intensity analysis. $(n=3)$. c CLSM images of CT26 and 3 T3 cells endocytosis. $\mathbf{d}$ MTT analysis. e Pharmacokinetic profiles after i.v. injection with PB@PCN and PB@PCN@MEM

\section{Multimodal imaging in vivo}

In general, treatment outcomes can be more effective if light-driven therapeutics are performed when agents reach the greatest accumulation at the tumor site. NPs with imaging modalities can monitor their accumulation in tumor sites during real-time systemic administration and provide guidance for treatment ${ }^{39}$. In most cases, the combination of multiple imaging modalities provides more detailed and accurate information for tumor diagnosis and treatment monitoring. Inspired by the superior ability of PB@PCN in solution, the in vivo multimodal imaging behavior of PB@PCN@MEM was further evaluated toward CT26 tumor-bearing mice. First, a FL study was performed on a small animal imaging system. As shown in Fig. 5a, an obvious fluorescence signal in the tumor region was observed $4 \mathrm{~h}$ after intravenous (i.v.) injection of PB@PCN@MEM. The PB@PCN@MEM fluorescence intensity reached its maximum after $8 \mathrm{~h}$ and remained at its maximum until $24 \mathrm{~h}$, indicating that PB@PCN@MEM had a good retention effect in tumors. Subsequently, the fluorescence in the tumor site gradually decreased from $24 \mathrm{~h}$ to $36 \mathrm{~h}$. Although PB@PCN accumulated to a certain extent in the tumor region due to the enhanced permeability and retention (EPR) effect, this accumulation was significantly weaker than that of PB@PCN@MEM. This result was ascribed to the biologically derived coating of $\mathrm{PB} @ \mathrm{PCN} @ \mathrm{MEM}$, which enabled the NPs to evade the immune system and possess an intrinsic self-targeting ability, achieving a long blood circulation time and homologous tumor cell targeting simultaneously. The mice were killed at $48 \mathrm{~h}$ postinjection, and the major organs were harvested for ex vivo imaging, and similar trends were observed (Fig. 5a, b). In addition, the tumor-specific accumulation of 
a

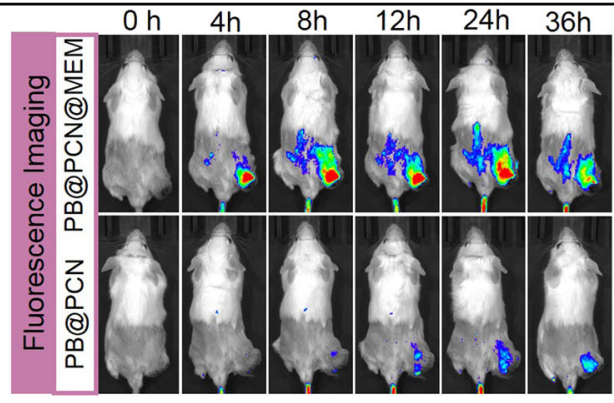

C

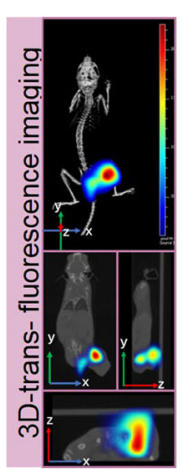

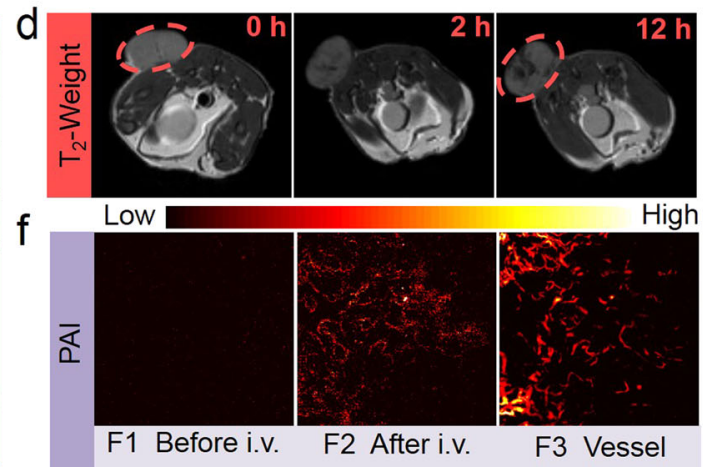
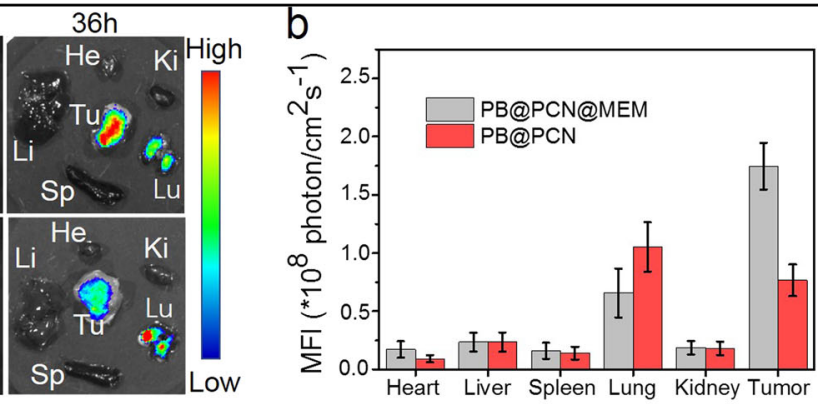

e

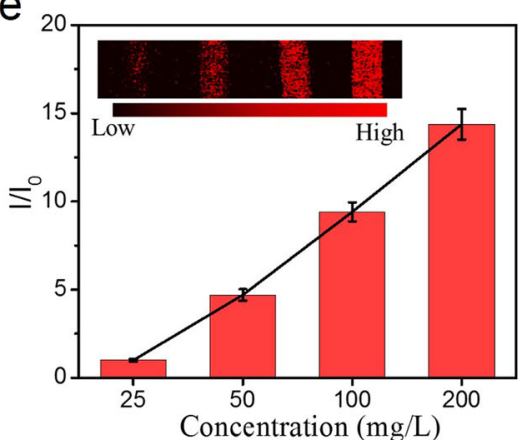

Fig. 5 Bioimaging in vivo. a The in vivo and ex vivo fluorescence images of CT26 tumor-bearing mice after intravenous (i.v.) injection of PB@PCN or PB@PCN@MEM for various time intervals. He, Li, Sp, Lu, Ki, and Tu stand for the heart, liver, spleen, lung, kidney, and tumor, respectively. b MFI analysis of the major organs and tumors $36 \mathrm{~h}$ after i.v. injection. $(n=3)$. $\mathbf{c}$ In vivo $3 \mathrm{D}$ reconstructed transillumination fluorescence imaging $12 \mathrm{~h}$ after intravenous injection of PB@PCN@MEM. d T2-weighted MR images of CT26 tumor-bearing mice taken at different time points after i.v. injection of PB@PCN@MEM. e In vitro PA signal images (inset) of PB@PCN solutions with different concentrations under $744 \mathrm{~nm}$ laser irradiation and the corresponding PA signal intensity. $\mathbf{f}$ In vivo PAl of tumor tissue before (f1) and $12 \mathrm{~h}$ after (f2) intravenous injection of PB@PCN@MEM under 744 nm laser irradiation, and (f3) imaging of vessel in the tumor site under $523 \mathrm{~nm}$ laser irradiation

PB@PCN@MEM was verified by the 3D reconstructed transillumination fluorescent image (Fig. 5c). Then, we evaluated the MRI contrast capability of PB@PCN@MEM. As shown in Fig. S26, with increasing NP concentrations, the $T_{2}$-weighted signals of the PB@PCN@MEM solution gradually darkened. Next, the mice bearing CT26 tumors were i.v. injected with PB@PCN@MEM and imaged under a 4.7 T MR imager. The $\mathrm{T}_{2}$-weighted MR signal became obviously darker at the tumor site over time, suggesting the significant accumulation of NPs in the tumor upon systemic administration (Fig. 5d). Owing to the NIR photothermal effect of PB@PCN@MEM, we explored its potential for in vivo PAI and IR. Figure 5e shows the PA signal of PB@PCN@MEM at different concentrations in tubes. In vivo PAI was carried out for CT26 tumor-bearing mice after i.v. injection with PB@PCN@MEM (Fig. 5f). Due to the tumor retention of PB@PCN@MEM, the PA signals, which were detected under $744 \mathrm{~nm}$ irradiation in the tumor region after $12 \mathrm{~h}$ (Fig. 5f2), were significantly enhanced compared with those at $0 \mathrm{~h}$ (Fig. 5f1), and the PA signal at $12 \mathrm{~h}$ was approximately five times as strong as that at $0 \mathrm{~h}$ (Fig. S27). Surprisingly, but completely understandably, the PA signal under $744 \mathrm{~nm}$ laser irradiation almost coincided with that under $523 \mathrm{~nm}$ irradiation (Fig. 5f3, imaging of vessel). This proved that systemically administered PB@PCN@MEM though the blood circulation system entered the tumor site and penetrated into the tumor tissue by the blood vessels of the tumor site. In addition, the IR in the tumor site after i.v. injection was detected (Fig. S28), indicating that PB@PCN@MEM could accumulate in the tumor region and achieve a good IR effect. All of the above results suggested that PB@PCN@MEM has excellent tumor targeting and in vivo bioimaging ability.

\section{Biocompatibility}

Biocompatibility and biosafety are critical to the application of nanomaterials in the biomedical field. Therefore, the biocompatibility and biosafety of PB@PCN and PB@PCN@MEM were evaluated through a series of characterizations. Since the stability of the NPs under physiological conditions is very important for the biomedical application of NPs in vivo, the stability of the NPs in PBS was studied before the biocompatibility study of the NPs. As shown in Fig. S29, PB@PCN@MEM was proved to have good stability and dispersion. Next, the hemocompatibility of the NPs was evaluated by the 


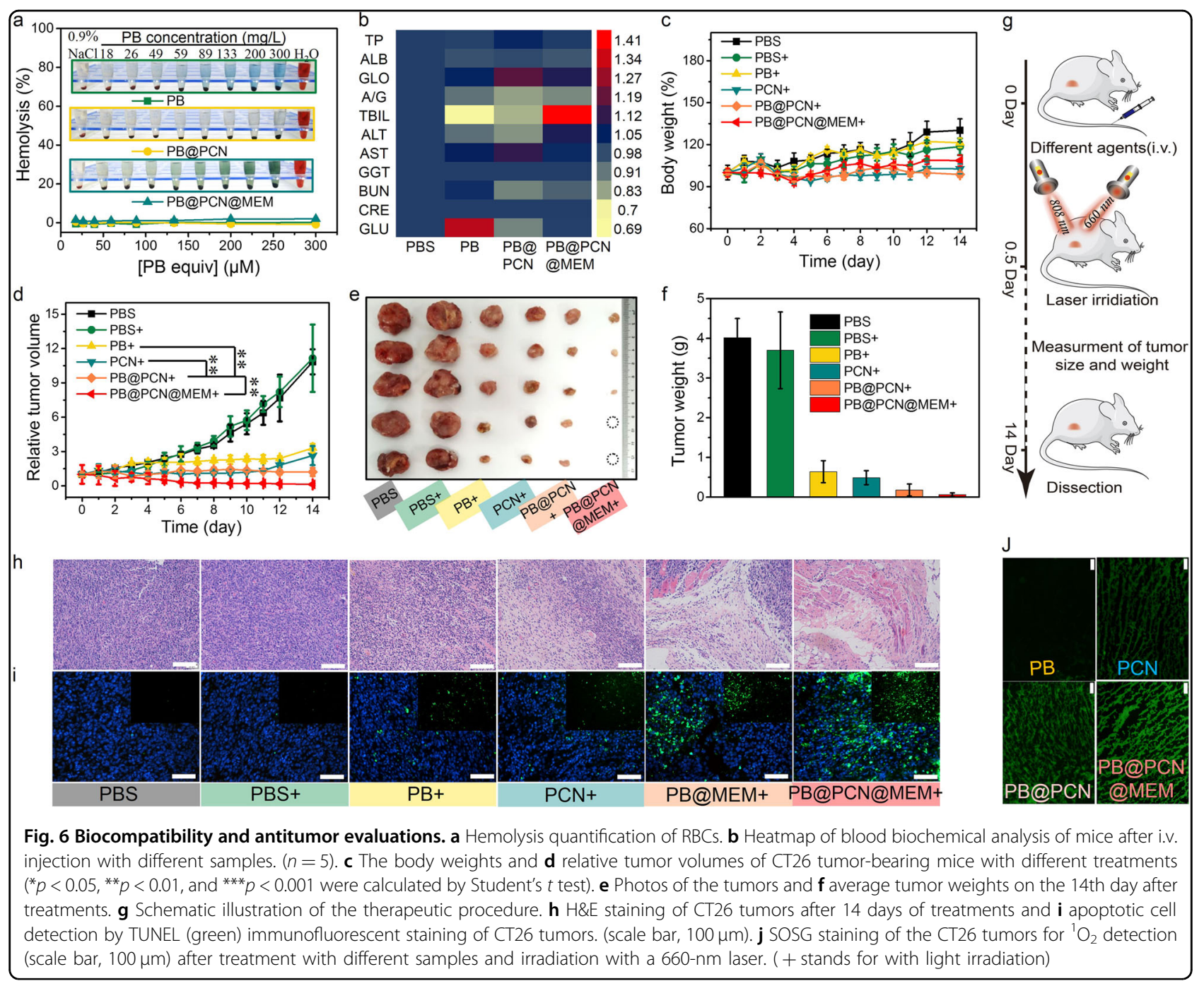

hemolysis test. From Fig. 6a, we can conclude that PB, $\mathrm{PB} @ \mathrm{PCN}$ and PB@PCN@MEM hardly caused hemolysis at high concentrations. Furthermore, the whole blood biochemical examination indicated that PB, PB@PCN and PB@PCN@MEM treatments had no significant effect on liver or kidney functions compared to the PBS group (Fig. $6 \mathrm{~b})$, and the main hematological parameters did not change significantly (Table S3). In addition, as shown in Fig. $6 \mathrm{c}$, after 14 days of treatments, there was negligible variation in the average weights in the different treatment groups, except for the PBS group, which displayed significantly larger tumors causing the mice to gain weight, which indicated that our treatments barely affected the health of the mice. We also studied the effects of different treatments on the major organs. The major organs of the different treatment groups were collected after 14 days of treatment, and hematoxylin and eosin (H\&E) staining was conducted (Fig. S30). There appeared to be no obvious physiological abnormalities in the major organs, including the hearts, livers, spleens, lungs, and kidneys. Collectively, these in vivo results demonstrated the good biocompatibility and low systemic toxicity of our nanomaterials.

\section{Antitumor effects}

Motivated by the above study of biocompatibility in vivo, the therapeutic effect of our nanomaterials was further assessed in CT26 tumor-bearing mice. The therapeutic procedure is shown in Fig. 6g. CT26 tumor-bearing mice were randomly divided into six groups (6 mice per group): PBS, PBS+, PB+, PCN+, PB@PCN+, PB@PCN@MEM (where + stands for with $660 \mathrm{~nm}$ and $808 \mathrm{~nm}$ light irradiation). Under the guidance of the multimodal imaging studies in vivo, at $12 \mathrm{~h}$ post i.v. injection of the corresponding therapeutic agent, the mice in the groups with light were exposed to $808 \mathrm{~nm}$ and $660 \mathrm{~nm}$ light for 5 and 4 min, respectively. The tumor sizes were measured over the following 2 weeks (Fig. 6d), and the tumors of all mice were collected (Fig. 6e) and weighed (Fig. 6f) on the 14th 
day. As revealed in these results, compared with the PBS/ $\mathrm{PBS}+$ groups, the $\mathrm{PB}+/ \mathrm{PCN}+$ groups exhibited a certain extent of tumor inhibition capacity mainly because of the EPR ability and PTT/PDT effects. Notably, due to the synergistic effects of PTT and enhanced PDT, the mice treated with $\mathrm{PB} @ \mathrm{PCN}+$ showed an excellent tumor growth inhibition effect, which was better than the $\mathrm{PB}+$ and $\mathrm{PCN}+$ treatment groups. As expected, the $\mathrm{PB} @ \mathrm{PCN} @ \mathrm{MEM}+$ group had the best therapeutic effect, and some tumors were even completely eliminated, which was ascribed to the tumor cell membrane coating endowing the NPs with the biological properties of homologous adhesion and immune escape. In addition to the analysis of the tumor size changes, the extracted tumors were sliced into sections for immunohistochemical assays. As revealed by H\&E staining (Fig. 6h), the most severe tumor damage (including vacuoles, condensed nuclei and changed cell shapes) was displayed in the PB@PCN@MEM + group. Furthermore, immunofluorescence staining showed the greatest cell apoptosis signal (Tunnel, Fig. 6i) and the weakest cell proliferation signal (Ki67, Fig. S31) in this group.

Next, we carefully studied the detailed mechanism of the effective combined PDT/PTT therapy in vivo. To prove that $\mathrm{PB} @ \mathrm{PCN}$ and $\mathrm{PB} @ \mathrm{PCN} @ \mathrm{MEM}$ catalyze $\mathrm{O}_{2}$ production to relieve the tumor hypoxic microenvironment, HIF- $\alpha$ immunofluorescence staining was carried out. As illustrated in Fig. S32, a significantly reduced red fluorescence (HIF- $\alpha$ expression) was observed in the tumor tissues after the intratumor injection of either $\mathrm{PB}$, $\mathrm{PB} @ \mathrm{PCN}$, or PB@PCN@MEM. Next, the in vivo ${ }^{1} \mathrm{O}_{2}$ generation was evaluated from the frozen sections of the tumor tissue after intratumoral injection of the mixtures of SOSG with PB, PCN, PB@PCN, and PB@PCN@MEM. After $660 \mathrm{~nm}$ laser irradiation, tumors treated with $\mathrm{PB} @ \mathrm{PCN}$ and PB@PCN@MEM displayed stronger green fluorescence than the tumors treated with PCN, while tumors treated with $\mathrm{PB}$ displayed almost no fluorescence (Fig. 6j), proving that PB@PCN and PB@PCN@MEM enhanced ${ }^{1} \mathrm{O}_{2}$ generation at the tumor site. Finally, according to the results of the above cell experiments, light-induced ${ }^{1} \mathrm{O}_{2}$ was capable of attacking HSPs, and the HSP70 expression levels in the tumors after different treatments were evaluated by immunofluorescent staining. As shown in Fig. S33, HSP70 expression obviously increased in the tumor after $808+660 \mathrm{~nm}$ irradiation in mice receiving an i.v. injection of $\mathrm{PB}$, indicating that $\mathrm{PB}$ was enriched at the tumor site and PTT was conducted. In marked contrast, a much lower tumor HSP70 expression level was detected after $808+660 \mathrm{~nm}$ irradiation with $\mathrm{PB} @ \mathrm{PCN}$ or $\mathrm{PB} @ \mathrm{PCN} @ M E M$ treatment, owing to the light-induced ${ }^{1} \mathrm{O}_{2}$-attacked HSP70. All of these results collectively showed that PB@PCN and PB@PCN@MEM treatments not only alleviated hypoxia in the TME and improved PDT efficiency but also reduced HSPs, which are upregulated after PTT.

\section{Conclusion}

In summary, a straightforward and convenient approach for the controlled construction of heterogeneous core/ shell PB@PCN nanohybrids was developed. A series of $\mathrm{PB} @ \mathrm{PCNs}$ with different shell thicknesses were prepared, and $\mathrm{PB} @ \mathrm{PCN}$ nanohybrids with the optimal thickness was used for efficient multi-image-guided combined PTT/ PDT therapy of tumors. This PB@PCN nanohybrid effectively combined the advantages of both the PB core and PCN shell to access collective properties beyond the intrinsic limitations of the individual components. This nanohybrid was able to overcome the limitation of hypoxia after PDT and HSP after PTT. After further coating with a homologous tumor cell membrane, the PB@PCN@MEM nanohybrid demonstrated homotypic targeting and immune-evading capacity. Monitored by multiple imaging techniques, PB@PCN@MEM could preferentially accumulate in the tumor after injection into the tail vein. This multifunctional nanohybrid with multimodal imaging ability for the combined PTT and PDT effects will find great potential for tumor treatment.

\section{Acknowledgements}

This work was supported by the National Natural Science Foundation of China (51833007, 51873161, and 51690152). All of the animal experiments were conducted under protocols approved by the Institutional Animal Care and Use Committee (IACUC) of the Animal Experiment Center of Wuhan University (Wuhan, China).

Conflict of interest

The authors declare that they have no conflict of interest.

\section{Publisher's note}

Springer Nature remains neutral with regard to jurisdictional claims in published maps and institutional affiliations.

Supplementary information is available for this paper at https://doi.org/ 10.1038/s41427-019-0164-4.

Received: 22 June 2019 Revised: 20 August 2019 Accepted: 27 August 2019.

Published online: 1 November 2019

\footnotetext{
References

1. Park, J., Jiang, Q.. Feng, D., Mao, L. \& Zhou, H. C. Size-controlled synthesis of porphyrinic metal-organic framework and functionalization for targeted photodynamic therapy. J. Am. Chem. Soc. 138, 3518-3525 (2016).

2. Song, G., Cheng, L., Chao, Y., Yang, K. \& Liu, Z. Emerging nanotechnology and advanced materials for cancer radiation therapy. Adv. Mater. 29, 1700996 (2017).

3. Fan, W., Yung, B., Huang, P. \& Chen, X. Nanotechnology for multimodal synergistic cancer therapy. Chem. Rev. 117, 13566-13638 (2017).

4. Shi, J., Kantoff, P. W., Wooster, R. \& Farokhzad, O. C. Cancer nanomedicine: progress, challenges and opportunities. Nat. Rev. Cancer 17, $20-37$ (2017).

5. $\mathrm{Pi}$, F. et al. Nanoparticle orientation to control RNA loading and ligand display on extracellular vesicles for cancer regression. Nat. Nanotechnol. 13, 82-89 (2018).
} 
6. He, X. Y. et al. Functional polymer/inorganic hybrid nanoparticles for macrophage targeting delivery of oligodeoxynucleotides in cancer immunotherapy. Mater. Today Chem. 4, 106-116 (2017).

7. Zhu, X. et al. Upconversion nanocomposite for programming combination cancer therapy by precise control of microscopic temperature. Nat. Commun. 9. 2176 (2018).

8. Wang, S. et al. H. A facile one-pot synthesis of a two-dimensional $\mathrm{MoS}_{2} / \mathrm{Bi}_{2} \mathrm{~S}_{3}$ composite theranostic nanosystem for multi-modality tumor imaging and therapy. Adv. Mater. 27, 2775-2782 (2015).

9. He, X. et al. Redox-active AlEgen-derived plasmonic and fluorescent core@shell nanoparticles for multimodality bioimaging. J. Am. Chem. Soc. 140, 6904-6911 (2018)

10. Wang, $H$. et al. A biomimetic hybrid nanoplatform for encapsulation and precisely controlled delivery of theranostic agents. Nat. Commun. 6, 10081 (2015).

11. Yang, Q. et al. Regulating the spatial distribution of metal nanoparticles within metal-organic frameworks to enhance catalytic efficiency. Nat. Commun. 8 , 14429 (2017).

12. Zhang, W. et al. Mesoporous metal-organic frameworks with size-, shape-, and space-distribution-controlled pore structure. Adv. Mater. 27, 2923-2929 (2015).

13. $\mathrm{Ma}$, $\mathrm{X}$. et al. Single gold-bridged nanoprobes for identification of single point DNA mutations. Nat. Commun. 10, 836 (2019).

14. Lu, G. et al. Imparting functionality to a metal-organic framework material by controlled nanoparticle encapsulation. Nat. Chem. 4, 310-316 (2012)

15. Bin, D. S. et al. Controlling the compositional chemistry in single nanoparticles for functional hollow carbon nanospheres. J. Am. Chem. Soc. 139 13492-13498 (2017)

16. Gai, S. et al. Recent advances in functional nanomaterials for light-triggered cancer therapy. Nano Today 19, 146-187 (2018).

17. Qi, J. et al. Light-driven transformable optical agent with adaptive functions for boosting cancer surgery outcomes. Nat. Commun. 9, 1848 (2018).

18. Chechetka, S. A. et al. Light-driven liquid metal nanotransformers for biomedical theranostics. Nat. Commun. 8, 15432 (2017).

19. Yu, X. et al. CT/MRI-guided synergistic radiotherapy and X-ray inducible photodynamic therapy using Tb-doped Gd-W-nanoscintillators. Angew. Chem. Int. Ed. 58, 2017-2022 (2019).

20. Ni, D. et al. Magnetic targeting of nanotheranostics enhances cerenkov radiation-induced photodynamic therapy. J. Am. Chem. Soc. 140, 14971-14979 (2018).

21. Zhu, H., Cheng, P., Chen, P. \& Pu, K. Recent progress in the development of near-infrared organic photothermal and photodynamic nanotherapeutics. Biomater. Sci. 6, 746-765 (2018).

22. Guo, W., Guo, C., Zheng, N., Sun, T. \& Liu, S. Csx WO $\mathrm{WO}_{3}$ nanorods coated with polyelectrolyte multilayers as a multifunctional nanomaterial for bimodal imaging-guided photothermal/photodynamic cancer treatment. Adv. Mater. 29, 1604157 (2017).
23. Cai, Y. et al. Diketopyrrolopyrrole-triphenylamine organic nanoparticles as multifunctional reagents for photoacoustic imaging-guided photodynamic/ photothermal synergistic tumor therapy. ACS Nano. 11, 1054-1063 (2017).

24. Goel, S. et al. Activatable hybrid nanotheranostics for tetramodal imaging and synergistic photothermal/photodynamic therapy. Adv. Mater. 30, 1704367 (2018).

25. Liu, Y. et al. Modulating hypoxia via nanomaterials chemistry for efficient treatment of solid tumors. Acc. Chem. Res. 51, 2502-2511 (2018).

26. Yang, $\mathrm{G}$. et al. Hollow $\mathrm{MnO}_{2}$ as a tumor-microenvironment-responsive biodegradable nano-platform for combination therapy favoring antitumor immune responses. Nat. Commun. 8, 902 (2017).

27. Liu, W. L. et al. Aggressive man-made red blood cells for hypoxia-resistant photodynamic therapy. Adv. Mater. 30, e1802006 (2018).

28. Kim, J. et al. Continuous $\mathrm{O}_{2}$-evolving $\mathrm{MnFe}_{2} \mathrm{O}_{4}$ nanoparticle-anchored mesoporous silica nanoparticles for efficient photodynamic therapy in hypoxic cancer. J. Am. Chem. Soc. 139, 10992-10995 (2017).

29. Lan, G. et al. Nanoscale metal-organic framework overcomes hypoxia for photodynamic therapy primed cancer immunotherapy. J. Am. Chem. Soc. 140, 5670-5673 (2018).

30. Chen, W. H. et al. Overcoming the heat endurance of tumor cells by interfering with the anaerobic glycolysis metabolism for improved photothermal therapy. ACS Nano. 11, 1419-1431 (2017).

31. Chu, K. F. \& Dupuy, D. E. Thermal ablation of tumours: biological mechanisms and advances in therapy. Nat. Rev. Cancer 14, 199-208 (2014).

32. Yang, $Y$. et al. 1D Coordination polymer nanofibers for low-temperature photothermal therapy. Adv. Mater. 29, 199 (2017).

33. Li, S. Y. et al. Cancer cell membrane camouflaged cascade bioreactor for cancer targeted starvation and photodynamic therapy. ACS Nano. 11, 7006-7018 (2017)

34. Xie, W. et al. Cancer cell membrane camouflaged nanoparticles to realize starvation therapy together with checkpoint blockades for enhancing cancer therapy. ACS Nano. 13, 2849-2857 (2019).

35. Parodi, A. et al. Synthetic nanoparticles functionalized with biomimetic leukocyte membranes possess cell-like functions. Nat. Nanotechnol. 8, 61-68 (2013).

36. Tang, Z. et al. Pyroelectric nanoplatform for NIR-II-triggered phototherma therapy with simultaneous pyroelectric dynamic therapy. Mater. Horiz. 5, 946-952 (2018).

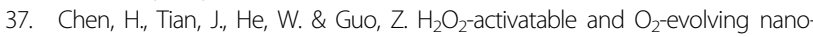
particles for highly efficient and selective photodynamic therapy against hypoxic tumor cells. J. Am. Chem. Soc. 137, 1539-1547 (2015).

38. Liu, Y. et al. One-dimensional Fe 2 P acts as a fenton agent in response to NIR II light and ultrasound for deep tumor synergetic theranostics. Angew. Chem. Int. Ed. 58, 2407-2412 (2019).

39. Liu, Y., Bhattarai, P., Dai, Z. \& Chen, X. Photothermal therapy and photoacoustic imaging via nanotheranostics in fighting cancer. Chem. Soc. Rev. 48, 2053-2108 (2019). 